\title{
Treze Passos para - Juízo Final: A Nova Era do Desarmamento Nuclear dos Estados Unidos e da Rússia*
}

Diego Santos Vieira de Jesus**

$\mathbf{U}_{\mathrm{m}}$ dos passos mais significativos rumo ao desarmamento nuclear foi dado na sexta Conferência de Revisão do Tratado de Não-Proliferação Nuclear (TNP), em 2000. Na ocasião, foi estabelecido um plano de ação de treze pontos práticos para a implementação sistemática do artigo VI do $\operatorname{tratado}^{1}$ ao longo de cinco anos. Tal plano representava o compromisso político mais preciso sobre medidas de desarmamento nuclear aceito pelas potências atômicas (RAUF, 2001, p. 12) e previa: 1) a entrada em vigor do Tratado sobre Proibição Completa dos Testes Nucleares (em inglês, Comprehen-

\footnotetext{
*Artigo recebido em julho e aprovado para publicação em setembro de 2007.

**Doutorando em Relações Internacionais pelo Instituto de Relações Internacionais da Pontifícia Universidade Católica do Rio de Janeiro (IRI/PUC-Rio) e professor da graduação em Relações Internacionais do IRI/PUC-Rio. E-mail: dsvj@infolink.com.br.
} 
sive Nuclear-Test-Ban Treaty (CTBT)); 2) a moratória dos testes nucleares até a entrada em vigor deste tratado; 3 ) a negociação de um Tratado sobre Banimento da Produção de Materiais Físseis (em inglês, Fissile Material Cut-off Treaty (FMCT)) não-discriminatório, multilateral e efetivamente verificável; 4) o estabelecimento, na Conferência sobre Desarmamento, do corpo subsidiário para desarmamento nuclear; 5) a aplicação do princípio da irreversibilidade às medidas de desarmamento e redução nucleares; 6) o empreendimento inequívoco de eliminação dos arsenais atômicos; 7) a entrada em vigor do segundo Tratado sobre Redução de Armas Ofensivas Estratégicas (em inglês, Strategic Arms Reduction Treaty (START II)), a assinatura do START III e o fortalecimento do Tratado sobre Limitação de Sistemas Antimísseis Balísticos (em inglês, Anti-Ballistic Missile Treaty (ABM Treaty ou ABMT)); 8) a Iniciativa Trilateral entre os EUA, a Rússia e a Agência Internacional de Energia Atômica (AIEA) para proteção de material nuclear; 9) a tomada de medidas como reduções unilaterais, transparência sobre capacidades e acordos, reduções nucleares não estratégicas e diminuição do status operacional de armas nucleares e de seu papel nas políticas de segurança; 10) a submissão do excesso de material físsil para fins militares à AIEA ou a outro mecanismo de verificação internacional, e a disponibilidade desse material para fins pacíficos; 11) a reafirmação do objetivo de desarmamento completo sob controle internacional efetivo; 12) a elaboração de relatórios regulares sobre a implementação das obrigações contidas no artigo VI; e 13) o desenvolvimento de capacidades de verificação dos acordos sobre desarmamento nuclear (APPLEGARTH, 2005).

Apesar da determinação inicial das grandes potências nucleares quanto ao plano, medidas estipuladas em 2000 não foram implementadas, e algumas foram abandonadas nos anos seguintes pelos EUA e pela Rússia, o que, a meu ver, teve um impacto extremamente negativo na construção de uma relação mais segura entre estas potências e 
no avanço efetivo na agenda de desarmamento nuclear. Minha posição é a de que, ao se abandonarem medidas tão precisas que permitiriam a ampliação da cooperação entre tais poderes e que garantiriam maior estabilidade na interação entre Estados dotados de capacidades militares com avançado potencial de destruição, são descartados importantes mecanismos que viabilizariam maior previsão dos níveis de forças em face de alterações futuras do contexto estratégico, além de se gerarem estímulos para que outros Estados desenvolvam sistemas nucleares a fim de se defenderem de possíveis agressões conduzidas por essas potências. Acredito que, em nome da busca de maior autonomia - em especial para lidar com novas ameaças no âmbito internacional -, os conceitos de mecanismos robustos tradicionais para o controle e a redução de armas nucleares foram sendo gradativamente erodidos em uma nova era marcada pela garantia de maiores liberdade de ação e autonomia para o planejamento militar pelas potências e pela ênfase na flexibilidade estratégica. Porém, como indicarei ao longo deste artigo, essa mais recente orientação teve, na minha percepção, efeitos deletérios, como a redução da previsibilidade na relação estratégica entre as duas maiores potências atômicas e a oferta de estímulos para o desenvolvimento de armas nucleares por outros Estados.

Como exemplo das decisões tomadas pelas lideranças das duas maiores potências atômicas nessa nova era, cabe citar a Revisão da Postura Nuclear (em inglês, Nuclear Posture Review (NPR)) norte-americana, a qual recomendava em 2001 um planejamento estratégico que, segundo a administração Bush (CROUCH, 2002; FEITH, 2002; RUMSFELD, 2002a), diminuiria o papel das armas nucleares na política de segurança ao integrá-las a sistemas ofensivos não nucleares, defesas ativas e passivas e infra-estrutura revitalizada para manutenção desses sistemas. Porém, o documento reafirma tais armas como elementos fundamentais nas capacidades de defesa, propondo o desenvolvimento de novos sistemas nucleares (SCHEINMAN, 2005). O engajamento em um desarmamento com- 
pleto foi rompido em 2002, quando a Diretiva Presidencial sobre Segurança Nacional 17 confirmou que armas nucleares estavam inclusas nas opções de retaliação em face de ataques com armas de destruição em massa (em inglês, weapon of mass destruction (WMD)) (BOESE, 2005a; KIMBALL; KUCIA, 2003; YOST, 2005, p. 93).

Alegando que o ABMT impedia a exploração das opções de proteção contra ataques de mísseis por Estados-párias ou grupos terroristas, Bush optou pela denúncia do tratado. Apesar de norte-americanos e russos terem dito que isso não abalaria a Nova Relação Estratégica, o presidente russo Vladimir Putin deixou claro que consideraria o START II - que teria banido mísseis balísticos intercontinentais (em inglês, intercontinental ballistic missile (ICBMs)) com múltiplas ogivas - definitivamente morto (WOOLF, 2002). O princípio da irreversibilidade nas reduções nucleares e o desenvolvimento de capacidades de verificação foram ignorados no Tratado sobre Reduções Ofensivas Estratégicas (em inglês, Strategic Offensive Reductions Treaty (SORT)), de 2002. Como já desenvolvi em trabalho anterior (JESUS, 2005), o tratado admite que EUA e Rússia determinem a composição de forças estratégicas e não estipula a destruição de ogivas, possibilitando que sejam removidas do desdobramento ${ }^{2}$ e armazenadas. Ele também não inclui definições detalhadas de sistemas, regras de contagem ou procedimentos para verificação (BLEEK, 2002b). Mesmo afirmando que não pretende retomar os testes nucleares suspensos em 1992, o Executivo norte-americano recusou-se a submeter o CTBT - que impediria o desenvolvimento de novos tipos de ogivas nucleares - para a reconsideração do Senado após o veto do Legislativo em 1999, e procurou melhorar as condições preparatórias de testes (YOST, 2005, p. 97). Em 2004, Bush anunciou que uma verificação efetiva do FMCT exigiria um regime de inspeção tão intrusivo que não era "realisticamente possível", 3 e decidiu apoiar negociações do tratado sem mecanismos de verificação (BOESE, 2005a; PREEZ, 2005). 
Em face da deterioração das forças convencionais desde o colapso da União das Repúblicas Socialistas Soviéticas (URSS), a Nova Doutrina Militar da Rússia ampliou a ênfase nas armas nucleares - em especial não estratégicas - na proteção da integridade territorial da federação (IVANOV, 2004). Entre 2000 e 2005, membros do governo russo explicitaram que as armas nucleares poderiam ser utilizadas não apenas em uma guerra de grande escala envolvendo potências nucleares, mas em conflitos menores na periferia do país. Apesar de terem reafirmado que não utilizariam armas nucleares contra Estados-parte do TNP que não tivessem tais sistemas, autoridades do Executivo russo reservaram o direito de usá-las para "repelir a agressão armada" - em especial ataques com armas químicas e biológicas - se outras respostas falhassem (ARBATOV, 2005; KIMBALL, 2005a). Com o anúncio da denúncia do ABMT pelos EUA em 2001 e a adesão de sete países do Leste Europeu à Organização do Tratado do Atlântico Norte (OTAN) em 2004, Putin reafirmou a cooperação com os países norte-atlânticos, mas declarou que a Rússia desenvolvia capacidades estratégicas "que nenhuma outra potência nuclear terá nos próximos anos”, como ogivas manobráveis de alta precisão e sistemas de lançamento avançados. ${ }^{4}$ Após o SORT, o Executivo russo não demonstrou disposição de negociar mais reduções ofensivas estratégicas nem não estratégicas, revelando a falta de comprometimento com a busca de medidas para desarmamento nuclear completo (GOTTEMOELLER, 2004; NORRIS; KRISTENSEN, 2004; 2005).

Diante desse quadro, o plano de ação de 2000 não foi efetivamente implementado: em 2005, o CTBT não tinha entrado em vigor, as negociações para um FMCT efetivamente verificável não começaram, o ABMT e o START II foram abandonados, o papel das armas nucleares não foi reduzido nas políticas de segurança, a maioria das reduções nucleares não eram irreversíveis ou verificáveis, o corpo subsidiário sobre desarmamento nuclear não foi estabelecido e a Iniciativa 
Trilateral permaneceu travada diante dos altos custos de implementação (JOHNSON, 2005; GOTTEMOELLER, 2004). Embora, a meu ver, as lideranças dos EUA e da Rússia tentem demonstrar que buscam demolir as barreiras da época da Guerra Fria que ainda perpassam seu relacionamento e procurem redefinir suas estratégias nucleares com objetivo de lidar com novas ameaças, a não-implementação e o abandono de medidas minuciosas que visem garantir a segurança e a previsibilidade na relação entre essas potências reduzem a transparência e minam a confiança mútua, em um momento em que cada lado tem a liberdade de preservar ogivas e capacidades de lançamento extras e que uma série de sistemas nucleares - como os não estratégicos - são simplesmente marginalizados nas principais discussões entre os membros dos Executivos desses países. Ademais, acredito que a postura até mesmo negligente com relação a tal plano de ação evidencie não apenas a falta de comprometimento dessas potências com um desarmamento nuclear efetivo, mas também com os objetivos de não-proliferação: no caso russo particularmente, o armazenamento de sistemas excedentes maximiza riscos potenciais, já que eles podem ser vendidos ou mesmo roubados por organizações terroristas.

Nesse contexto, grande parte dos autores da área de controle de armas e desarmamento pareceu mais preocupada em avaliar os impactos das decisões das duas maiores potências atômicas quanto à agenda de desarmamento nuclear e/ou em esboçar motivações imprecisas dessas ações, particularmente nos debates em torno: do papel das armas nucleares no planejamento estratégico norte-americano; ${ }^{5}$ da denúncia do ABMT pelos EUA $;^{6}$ do descaso dos EUA e da Rússia com a irreversibilidade das reduções e o desenvolvimento de capacidades de verificação, que tiveram como foco o SORT; ${ }^{7}$ e do interesse russo em desenvolver novas armas nucleares, com ênfase no período posterior ao plano de modernização das forças estratégicas estabelecido pelo Ministério da Defesa. ${ }^{8}$ Apesar da rica avaliação de méritos e li- 
mitações das ações das duas grandes potências e da ênfase nos determinantes internacionais gerais de seu comportamento - como a necessidade de as potências responderem a um novo ambiente estratégico, em que se tornam cada vez mais evidentes as ações de Estados que desafiam regimes de segurança, bem como atores não estatais que não são limitados pelas normas internacionais -, a maior parte dessas análises transmitiu a idéia de que teria existido consenso entre formuladores de decisão quanto às ações implementadas - o que pode não refletir a realidade dos fatos. Se tal conformidade realmente existiu em alguns casos, não se examinou como foi atingida. Além disso, a literatura deu atenção marginal à interação entre fatores domésticos e internacionais que explicam as decisões desses Executivos, mais precisamente à influência recíproca entre dois processos: a interação estratégica entre negociadores dos governos e as barganhas domésticas para a obtenção de consentimento às propostas do Executivo. Foram omitidas as barganhas entre membros do Executivo e deles com demais atores - como membros do Legislativo e principais grupos de interesse -, e a distribuição de poder decisório pelas instituições domésticas. A literatura ignorou estratégias do Executivo na conciliação dos imperativos domésticos e internacionais e desprezou barganhas internas que determinaram posturas estratégicas e posições iniciais dessas potências nas negociações posteriores ao estabelecimento do plano de ação acerca de temas relacionados aos treze pontos. A abordagem que desenvolverei tem como objetivos justamente superar essas limitações e buscar um entendimento mais complexo e minucioso das ações dos EUA e da Rússia em relação ao plano de ação de 2000.

Partindo da posição de que a implementação completa desses compromissos políticos pelas duas maiores potências atômicas poderia reduzir incentivos para o desenvolvimento de armas nucleares por outros Estados e criar mecanismos que ampliassem a transparência e a previsibilidade na interação entre os detentores dos maiores arse- 
nais nucleares do planeta, procuro explicar por que os líderes dos EUA e da Rússia não implementaram total e efetivamente o plano de ação de treze pontos práticos sobre desarmamento nuclear. As decisões dos membros dos Executivos desses países relacionadas aos treze pontos serão vistas como resultados da conciliação de imperativos internos e externos por tais indivíduos, que enfrentam oportunidades e dilemas estratégicos distintos simultaneamente nos âmbitos doméstico e internacional. Serão consideradas escolhas políticas de membros dos Executivos nacionais e estrangeiros, Legislativos e principais grupos de interesse, bem como a distribuição de poder sobre a formulação da decisão, estabelecida pelas instituições domésticas. Será aplicada a perspectiva dos jogos de dois níveis (PUTNAM, 1988; MILNER, 1997; MORAVCSIK, 1993). A fim de obter maior detalhamento na análise da formulação das posturas estratégicas e posições negociadoras iniciais posteriores ao estabelecimento do plano de ação acerca de temas relacionados aos treze pontos, complementarei essa perspectiva com a promoção de seu diálogo com o modelo da política burocrática (ALLISON, 1971).

Busco averiguar a correção da suposição de que, nos EUA, os neoconservadores que compunham o grupo dos "vulcanos" - os principais conselheiros de George W. Bush para política externa e segurança nacional - ocuparam a maior parte dos principais cargos relacionados à formulação da política externa e de segurança norte-americana, em especial no Departamento de Defesa e no Gabinete presidencial. Tendo responsabilidade formal sobre assuntos de segurança estratégica e controle sobre instituições, recursos e informações necessários à implementação das ações governamentais, esses indivíduos - com cujas posições o presidente mais se identificava - estabeleceram o direcionamento da política nuclear da administração Bush, vencendo as posições mais moderadas no Departamento de Estado ao enfatizarem a preservação da flexibilidade para modernizar e operar forças estratégicas e táticas contra Estados-párias e orga- 
nizações terroristas em busca de WMD e, em uma situação mais remota, potências como China ou Rússia no caso de reversão da cooperação. A fim de atender a contingências imediatas, imprevistas e potenciais, Bush e os principais membros de sua equipe buscaram autonomia para 1) desenvolver e desdobrar todas as opções possíveis de defesas antimísseis; 2) determinar a composição das forças ofensivas estratégicas e não estratégicas sem os constrangimentos trazidos por acordos dotados de mecanismos de verificação excessivamente intrusivos, que impusessem amplas restrições à operação de armas nucleares; e 3) se necessário, retomar testes nucleares para a fabricação de novos modelos de ogivas e sanar falhas nos existentes. Esta orientação inicial foi consolidada na NPR e reforçada nos anos seguintes em face da conciliação feita por Bush e membros de sua equipe entre a necessidade estratégica de defesa do país e seus aliados diante da proliferação de WMD para Estados-párias e grupos terroristas no âmbito internacional e da pressão doméstica de republicanos e de parte dos democratas no Legislativo - a maioria do Congresso, dotada de poderes de ratificação, veto e emenda sobre a maior parte da agenda internacional - e de setores das Forças Armadas pelo reforço da flexibilidade estratégica. Nesse contexto, inserem-se as decisões que revelaram a negligência ao plano de ação de 2000, como a denúncia unilateral do ABMT, a assinatura de acordos sem mecanismos próprios de verificação, como o SORT, a recusa à reapresentação do CTBT para conselho e consentimento para ratificação, a imposição de obstáculos a um FMCT efetivamente verificável e o reforço do papel das armas nucleares na política de segurança.

No caso russo, procuro investigar a correção da suposição de que, após intensas batalhas burocráticas iniciais sobre reformas militares entre sergeyevistas e kvashnistas ${ }^{9}$ no governo russo, as preocupações em torno da proliferação de WMD na periferia do país, do desenvolvimento da defesa antimísseis norte-americana e das pesquisas nos EUA sobre armas nucleares para teatros de operações moti- 
varam o acordo entre as lideranças da Rússia em torno do reforço do papel das armas nucleares na política de segurança. Com base nessa posição inicial, o presidente Vladimir Putin e os membros de sua equipe buscaram evitar os obstáculos políticos e jurídicos à sua flexibilidade estratégica e valorizaram ainda mais a autonomia no planejamento militar. A ênfase no papel das armas nucleares foi reforçada nos anos seguintes em virtude de uma interação de dois fatores: 1) necessidade militar e estratégica internacional, dada a fraqueza das forças convencionais para lidar com as novas ameaças externas; e 2) benefícios políticos domésticos, assegurando a membros da Duma (câmara baixa do Parlamento Russo) e do Conselho da Federação (câmara alta do mesmo Parlamento) - dotados de poderes de ratificação e veto sobre grande parte das decisões do Executivo acerca de matérias de política externa e segurança nacional - e aos setores militares internos - os principais grupos de interesse envolvidos - que, mesmo com o reforço da cooperação com EUA e Europa Ocidental, as contramedidas russas estavam em pleno funcionamento no caso da reversão dessa relação cooperativa e em face da presença militar da OTAN nas proximidades das fronteiras do país. Tendo isso em vista, Putin optou pelo abandono do START II, pela modernização do arsenal nuclear russo e pelo desdobramento de armas não estratégicas, rompendo com os compromissos de 2000. Com isso, visava atender às pressões de coalizões políticas domésticas essenciais ao governo e proteger a soberania e a integridade territorial do país contra qualquer agressor, fossem o terrorismo internacional e os Estados em busca de WMD na periferia ou mesmo Estados avançados econômica, tecnológica e militarmente.

Na próxima seção, apresentarei a perspectiva dos jogos de dois níveis e o modelo da política burocrática e evidenciarei como pretendo promover o diálogo entre tais abordagens. A seguir, investigarei o processo de definição das posturas estratégicas e posições negociadoras iniciais posteriores ao estabelecimento do plano de ação acerca de temas 
relacionados aos treze pontos. O objetivo será evidenciar as bases a partir das quais o jogo interativo entre a dimensão doméstica e internacional se desenvolveu. Posteriormente, na consideração do jogo em questão, examinarei o impacto das escolhas políticas dos atores envolvidos e da distribuição de poder decisório estabelecida pelas instituições domésticas sobre as ações tomadas pelas duas potências, que, a meu ver, preservam a liberdade de ação dos EUA e da Rússia, mas não contribuem para um genuíno desarmamento nuclear.

\section{Os Jogos de Dois Níveis e o Modelo da Política Burocrática}

Na lógica dos "jogos de dois níveis", forças nacionais perseguem seus interesses em âmbito doméstico pressionando o Executivo para que adote medidas favoráveis, enquanto este procura ampliar poder de barganha formando coalizões entre elas. Em âmbito internacional, o Executivo procura satisfazer interesses domésticos, enquanto tenta minimizar conseqüências adversas dos desenvolvimentos externos (PUTNAM, 1988, p. 434). De forma distinta a abordagens que enfocam exclusivamente demandas internas ou a lógica sistêmica do "interesse nacional" pré-dado e que tratam os níveis doméstico e internacional como superpostos (Moravcsik, 1993, p. 15), acredito que a perspectiva dos jogos de dois níveis permita sanar as insuficiências dessas perspectivas analíticas ao criar um arcabouço complexo para a análise do impacto combinado dos fatores internos e externos na negociação internacional, sendo, na minha visão, adequada para examinar as decisões dos EUA e da Rússia em relação aos pontos do plano de ação, tomadas no âmbito das negociações bilaterais e multilaterais dos EUA e da Rússia.

De forma mais precisa, Robert Putnam (1988, p. 436-438) decompõe analiticamente esse processo em Nível I - barganha entre negociado- 
res na mesa internacional - e em Nível II - discussões, na esfera doméstica, acerca do consentimento para as propostas do Executivo -, de forma que a necessidade desse consentimento no Nível II afeta a barganha no I. O win-set é o conjunto dos acordos possíveis no Nível I que seriam aceitos no II, e seu tamanho relativo afeta a distribuição dos ganhos conjuntos da barganha internacional: quanto maior o win-set percebido do negociador, mais ele poderá ser conduzido a ceder aos outros no Nível I. Um win-set pequeno pode ser vantagem na barganha, pois restringe a capacidade de fazer concessões. ${ }^{10}$ Porém, corre-se o risco de se estabelecer uma posição imóvel que vá além da habilidade do outro lado de condescender. Isso pode provocar estagnação das negociações. Esse win-seté determinado pela distribuição de escolhas políticas e coalizões no Nível II; ${ }^{11}$ pelas instituições políticas do Nível II, pois os procedimentos domésticos para se obter consentimento para ratificação de acordos podem aumentar o poder de barganha ao reduzir o win-set, mas também ampliar o risco de deserção involuntária; ${ }^{12}$ e pelas estratégias dos negociadores do Nível I, como a oferta de compensações paralelas para atrair apoio doméstico. Um jogador maximizador de utilidade procura, por exemplo, convencer negociadores da outra parte de que seu win-set será aprovado, além de tentar reestruturar o jogo ou alterar visões dos outros sobre custos e benefícios dos entendimentos propostos. Seus principais objetivos são a busca de maximização de recursos políticos e a minimização de perdas potenciais. Os negociadores podem buscar sua própria concepção de interesse nacional no contexto internacional e mudar o equilíbrio de poder no nível doméstico em favor de políticas que preferem por razões exógenas (PUTNAM, 1988, p. 440-457).

Partindo dessa estrutura analítica, Helen Milner (1997) aponta que a interação entre os níveis internacional e doméstico se traduz em um jogo de negociação em que são consideradas as escolhas politicas ${ }^{13}$ dos jogadores visando a maximização de ganhos, as instituições po- 
líticas domésticas e a distribuição da informação. O conjunto de escolhas políticas refere-se às posições de atores domésticos que compartilham poder sobre a formulação da decisão - Executivo, Legislativo e grupos de interesse - e do Executivo estrangeiro. Cada um deseja uma política o mais próxima possível de seu "ponto ideal", e a utilidade declina linearmente conforme a política implementada se afasta desse ponto. Há menor probabilidade de cooperação internacional quando existem diferenças de escolhas entre atores políticos domésticos e os mais contrários à cooperação têm maior poder decisório. Os negociadores precisam antecipar a reação dos responsáveis pelo consentimento doméstico para a ratificação da proposta internacional e garantir que seja aceitável internamente (MILNER, 1997, p. 70-73, 237-238).

As instituições políticas determinam como o controle sobre a formulação da decisão é distribuído domesticamente, ou seja, como são compartilhados elementos como definição da agenda e poderes de emenda e ratificação/veto. Com tal controle, as escolhas do ator mais provavelmente estarão refletidas na decisão política final (MILNER, 1997, p. 18). O controle sobre agenda permite ao jogador definir termos do debate e estruturar alternativas para lidar com a questão. $\mathrm{O}$ poder de emenda permite ao autor fazer alterações que tragam o acordo para mais perto de seu ponto ideal, enquanto o de ratificação/veto limita o formulador de agenda ou aquele que tem poder de emenda (MILNER, 1997, p. 102-108).

Os atores têm preferências sobre políticas e instituições, pois certas instituições tornarão a realização de suas preferências mais provável. Nesse sentido, a escolha de procedimentos para desenvolver e ratificar políticas cooperativas também é objeto de disputa, de maneira que a forma como acordos são ratificados influencia a barganha internacional. Os procedimentos pelos quais se oferece consentimento para a ratificação de acordos determinam quem será o votante mediano cuja aceitação o Executivo deve assegurar, determinando os ato- 


\section{Diego Santos Vieira de Jesus}

res relevantes e, com isso, a própria estrutura de preferências domésticas. Quanto mais contenciosa for a questão, maior será o debate sobre tais procedimentos. As preferências dos atores quanto aos meios pelos quais se oferece consentimento para ratificação dos acordos seguem ligadas às suas preferências sobre a própria questão, tendo em vista que também farão escolhas sobre procedimentos. Eles podem tentar tornar-se os votantes medianos. Já quando os atores não têm informação completa sobre a questão, pode-se gerar resultados ineficientes e vantagens políticas para quem detém mais informação. ${ }^{14}$ É papel dos grupos de interesse prover de informação os atores ${ }^{15}$ (MILNER, 1997, p. 20-22).

As abordagens de Putnam (1988) e Milner (1997) enfatizam a interação estratégica entre os Executivos nacional e internacional e a dinâmica interna para consentimento à ratificação, mas não permitem analisar minuciosamente as barganhas políticas das quais resulta a posição negociadora inicial posterior ao estabelecimento do plano de ação acerca de temas relacionados aos treze pontos. A fim de vencer tal limitação, pretendo desenvolver o diálogo com o modelo da política burocrática de Graham Allison (1971, p. 162-181). Esta abordagem explica o comportamento do Estado pelo jogo de negociação, por meio de circuitos regularizados, entre indivíduos situados na política burocrática, que têm poder distinto sobre questões particulares e com objetivos separáveis em subjogos diversos. As posições de cada jogador nos canais de ação política definem suas vantagens e desvantagens, bem como suas obrigações. O poder - entendido como a influência sobre decisões governamentais - é uma combinação de vantagens de barganha, habilidade e vontade de usá-las e visões que outros jogadores têm desses elementos. As fontes dessas vantagens incluem autoridade formal, controle sobre recursos necessários à efetuação da ação, informação que permite estimar possibilidades e habilidade de afetar os objetivos de outros jogadores. As regras - vindas da Constituição, estatutos ou convenções sociais - esta- 
belecem os canais de ação de cada um, determinam decisões aceitáveis e impedem certas jogadas. Cada indivíduo deve olhar para bai$x o$, identificando opções para preservar margem de manobra; para o lado, a fim de manter o compromisso dos outros indivíduos e os atrair para sua coalizão; e para cima, a fim de certificar os superiores de que sua posição é a melhor (ALLISON, 1971, p. 144-177). Embora críticos enfatizem que o modelo de Allison é limitado à exploração da divergência de posições, apontarei que reduzi-lo à análise do dissenso é restringir seu potencial explicativo, já que ele capta a riqueza de detalhes e oferece maiores consistência e precisão à análise, mesmo que atores tenham escolhas semelhantes e os resultados da sua interação lembrem o comportamento do Estado como ator unitário.

Na promoção do diálogo entre tais abordagens, esta investigação, voltada para a análise da interação estratégica, será embasada na escolha racional $^{16}$ (KATZENSTEIN et al., 1998, p. 682; WENDT, 1999, p. 371). Embora Milner (1997) trabalhe com Executivos nacionais e estrangeiros, Legislativo e grupos de interesse como atores unitários, considerarei escolhas políticas de indivíduos maximizadores de utilidade que compõem esses conjuntos, tendo em vista a disponibilidade de dados minuciosos sobre suas posições individuais, garantindo-se maior precisão à análise. Será considerada como variável dependente a não-implementação total e efetiva do plano de ação pelos EUA e pela Rússia, e como variáveis independentes 1) as escolhas políticas maximizadoras de ganhos por indivíduos que compõem Executivos nacionais e estrangeiros, Legislativo e principais grupos de interesse ${ }^{17}$; e 2) as instituições políticas domésticas, que distribuem controle sobre a formulação da decisão. Será mantida a suposição de distribuição assimétrica de informação entre membros do Executivo nacional e Legislativo, de forma que caberá a membros de grupos de interesse oferecer informação acerca da natureza de questões e acordos. O recorte temporal da pesquisa estende-se de janeiro de 2001 - quando a recém-empossada administra- 
ção Bush e o governo Putin começam a desrespeitar ou abandonar os pontos do plano de ação - a maio de 2005 - prazo final para implementação efetiva do plano, na sétima Conferência.

Primeiramente, apresentarei o processo de barganha que levou à formação das novas posturas estratégicas dos EUA e da Rússia e da posição negociadora inicial posterior ao estabelecimento do plano de ação acerca de temas relacionados aos treze pontos no âmbito internacional. O foco será na barganha dentro do Executivo de cada país, já que esses são os principais responsáveis pela formulação da agenda de política externa e de segurança nacional. A seguir, ao investigar o jogo interativo entre as dimensões externa e interna, as negociações consideradas serão aquelas em nível bilateral, em especial entre essas grandes potências, e multilateral, particularmente a Conferência sobre Desarmamento e a AIEA.

\section{A Definição das Posturas Estratégicas e Posições Negociadoras Iniciais dos EUA e da Rússia}

Em 2001, George W. Bush apontou como prioridades de sua política de segurança estratégica o desdobramento da defesa antimísseis e a realização de reduções ofensivas estratégicas, iniciativas inseridas no contexto de uma redefinição da postura norte-americana para lidar com novos desafios do sistema internacional no século XXI: os Estados-párias e os grupos terroristas, especialmente aqueles em busca de WMD (DAVIS, 2002; JISHE, 2001; WOOLF, 2002; KARTCHNER, 2002). Ainda como candidato à Presidência da República, Bush deixou claro que tentaria modificar o ABMT a fim de desdobrar um sistema nacional de defesa antimísseis para atender às necessidades de segurança do mundo pós-Guerra Fria e, se os membros do Executivo russo se recusassem a emendar o tratado, sugeriu que poderia denunciar o acordo (BOESE, 2001a; 2001b; 2001c; 
GOLDGEIER; MCFAUL, 2002). Além disso, Bush planejava conduzir reduções ofensivas estratégicas compatíveis com as necessidades de segurança nacional, sem obrigatoriamente assinar tratados detalhados, complexos e robustos com a Rússia. Ele indicou que armas baseadas em um cenário estratégico ultrapassado eram "caros resquícios de conflitos mortos" (KERREY; HARTUNG, 2001). ${ }^{18} \mathrm{Me}-$ didas unilaterais para reduções ofensivas ganhavam força na posição de Bush, pois permitiriam maior flexibilidade que acordos robustos assinados no passado com a então URSS (atual Rússia), em um momento em que os EUA poderiam, com os novos arranjos, ajustar sua postura nuclear em resposta às ameaças futuras e tirar vantagem das mudanças tecnológicas que não seriam permitidas por um tratado no perfil do START I. As medidas unilaterais eram menos limitantes ao planejamento das forças estratégicas (GOTTEMOELLER, 2001). Ademais, Bush afirmou que o CTBT não seria novamente considerado, já que tal tratado não era a resposta para conter a proliferação. Se necessário, Bush pretendia retomar testes nucleares para a fabricação de novos modelos de ogivas e sanar falhas nos existentes (GOLDGEIER; MCFAUL, 2002; JISHE, 2001; KERREY; HARTUNG, 2001).

Tais posições, na minha percepção, representam um nítido retrocesso em relação às conquistas dos inúmeros instrumentos voltados para o desarmamento nuclear, desenvolvidos durante a Guerra Fria e na década posterior ao seu fim, tendo em vista o potencial que os posicionamentos de Bush têm para minar a confiança e a estabilidade na relação dos EUA com as demais potências nucleares e, principalmente, para estimular a proliferação por parte de outros atores que se sintam ameaçados com as ações implementadas pelos norte-americanos. Considero que os possíveis benefícios derivados dessa nova postura poderiam ser aniquilados pelos riscos próprios de uma política que autoriza a aplicação de sistemas atômicos em cenários de conflito local. Além de encorajar a proliferação, esse posicionamento contradiz 
o compromisso norte-americano, sob o artigo VI do TNP, de tomar medidas concretas com o objetivo de eliminar seu arsenal nuclear, reafirmado na sexta Conferência de revisão do tratado. Em face da imprevisibilidade das novas ameaças, compartilho a posição crítica de que Bush indiretamente propunha a diluição da fronteira entre sistemas necessários à dissuasão e aqueles voltados para a aplicação no campo de batalha, além de utilizar manobras discursivas a fim de mascarar sua falta de compromisso com um desarmamento nuclear genuíno: embora constantemente afirmasse que buscava superar o legado nuclear da Guerra Fria, Bush, na prática, preservava na política de segurança norte-americana o papel central dos sistemas atômicos, que seriam complementados por sistemas de defesa e pelo arsenal convencional.

As visões mais críticas que alertavam para diversos desses pontos foram gradativamente minadas nas discussões entre membros do Gabinete presidencial e do Conselho de Segurança Nacional. Em seu primeiro mandato, Bush nomeou Colin Powell secretário de Estado e Donald Rumsfeld secretário de Defesa e designou Condoleezza Rice conselheira de Segurança Nacional (BOESE, 2001a). Os indivíduos que ocupam tais postos compõem, com o presidente, o núcleo responsável pela formulação das principais decisões da política de segurança estratégica norte-americana, de acordo com as regras que estabelecem os canais de ação de cada um e os circuitos regularizados na política burocrática entre tais indivíduos, os quais têm poderes diversos sobre questões específicas (ALLISON, 1971). Segundo a Constituição, o presidente é o comandante-chefe do Exército e da Marinha e pode requerer a opinião dos principais funcionários de cada departamento executivo sobre qualquer questão relacionada aos deveres deles. Ele tem o poder de responder a ataques aos EUA, exceto em casos de impeachment; pode assinar tratados, que devem ter o consentimento de pelo menos dois terços dos senadores presentes para a ratificação; e nomear membros da sua equipe com o con- 
sentimento do Senado (ESTADOS UNIDOS DA AMÉRICA, s.d.). De acordo com a legislação norte-americana, o secretário de Estado é o principal conselheiro para assuntos de política externa no Gabinete presidencial; conduz negociações relacionadas aos principais assuntos de política externa; participa pessoalmente ou lidera grupos de representantes em conferências, organizações e agências internacionais; negocia e interpreta tratados e acordos com governos estrangeiros (ESTADOS UNIDOS DA AMÉRICA. Departamento de Estado, 2001). Já o secretário de Defesa é o principal conselheiro do presidente para a política de defesa norte-americana. É responsável pela formulação e pela execução da política geral de defesa da nação e, como o secretário de Estado, é membro do Gabinete presidencial (ESTADOS UNIDOS DA AMÉRICA. Casa Branca, 1947-1997; ESTADOS UNIDOS DA AMÉRICA. Departamento de Defesa, 2004). O conselheiro de Segurança Nacional assessora diretamente o presidente em questões sobre a segurança norte-americana (ESTADOS UNIDOS DA AMÉRICA. Casa Branca, 1947-1997).

Powell excluiu os conservadores das posições centrais em sua equipe e preencheu cargos de subsecretários com funcionários de carreira no serviço de relações exteriores, em uma tentativa de evitar que tais cargos fossem ocupados por indicados pela Casa Branca, cujas visões eram bastante opostas às do secretário de Estado (WALLER, 2001). Ele era adepto de uma postura mais moderada e cautelosa com respeito à segurança estratégica. Por exemplo, embora destacasse a importância da Defesa Nacional Antimísseis (em inglês, National Missile Defense (NMD)) para a segurança norte-americana, o secretário de Estado mostrava-se prudente em relação ao avanço da defesa antimísseis, enfatizando constantemente a necessidade de consultar os aliados dos norte-americanos, a Rússia e a China - receosos de que o desdobramento de uma NMD pudesse dar início a uma corrida armamentista renovada e disseminar a proliferação -, antes de conduzir o teste e o desdobramento de tal sistema. Afirmou que buscaria 
demonstrar aos líderes de outras nações que os membros da administração Bush viam a NMD como "um dos maiores interesses da população norte-americana" e que tentaria persuadir os russos acerca da necessidade de "ir além" da estrutura estabelecida pelo ABMT (BOESE, 2001a; KUPCHAN, 2002, p. 25-26; BUSH..., 2000-2001a; 2000-2001b). Powell também destacou a necessidade de redução de sistemas nucleares excedentes dos EUA e da Rússia e apontou as condições precárias de segurança de grande parte dessas armas em território russo. No passado, ele fora contra o uso de armas nucleares na Guerra do Golfo, além de já ter apoiado o CTBT e apontado a necessidade de continuar o diálogo com a Coréia do Norte sobre a limitação de programas de mísseis balísticos (KERREY; HARTUNG, 2001).

Porém, as posições do presidente Bush e do seu vice, Dick Cheney, identificavam-se mais com as de Rumsfeld e de Rice do que com o perfil mais moderado de Powell no que dizia respeito à defesa antimísseis e às reduções ofensivas estratégicas. Rumsfeld e Rice desejavam os rápidos desenvolvimento e desdobramento da defesa antimísseis e consideravam os densos e robustos tratados sobre controle e redução de armas assinados durante a Guerra Fria como resquícios de um ambiente estratégico ultrapassado. Rice manteve a ênfase na importância da NMD e observou que novos acordos sobre reduções ofensivas estratégicas nos moldes daqueles antigos tratados poderiam limitar excessivamente a flexibilidade norte-americana para lidar com as ameaças do novo ambiente estratégico internacional. Já Rumsfeld ${ }^{19}$ escolheu uma equipe com alguns dos neoconservadores mais reconhecidos de Washington, a fim de modificar o "perfil moribundo do Pentágono", que parecia "estar à deriva" (WALLER, 2001) durante a administração Clinton. Tal equipe incluía o vice-secretário de Defesa Paul Wolfowitz, o subsecretário de Defesa para Política Douglas Feith e, para a Política de Segurança Internacional, o secretário-adjunto J. D. Crouch (WALLER, 2001). Segun- 
do o então secretário de Defesa, os EUA deveriam garantir a capacidade de desenvolver, desdobrar e operar uma força altamente capaz de deter novas ameaças. Isso requeria uma reconfiguração das capacidades de dissuasão e de defesa, já que a antiga estratégia da Guerra Fria e da década que a seguiu era imperfeita e insuficiente para lidar com as ameaças do século XXI. As armas nucleares ofensivas estratégicas não tinham deixado de ser importantes para a garantia da segurança norte-americana, mas, no planejamento para o novo contexto internacional, o arsenal não precisava mais ter os mesmos tamanho e composição, que refletiam as necessidades de uma situação estratégica de dez anos antes. Tais armas continuariam a ter um papel decisivo, embora estivessem em menor número e compusessem uma estratégia caracterizada por uma maior diversidade de opções militares para lidar com as novas ameaças. De acordo com Rumsfeld, a dissuasão nuclear ainda era um elemento essencial da política de segurança norte-americana, mas uma estratégia caracterizada pela credibilidade precisava ser adaptada às circunstâncias do século XXI e baseada na combinação de capacidades ofensivas nucleares e não nucleares e sistemas defensivos, que negariam a adversários a oportunidade e os benefícios do uso de WMD contra os EUA ${ }^{20}$ (BUSH..., 2000-2001a).

John Bolton foi nomeado subsecretário de Estado para o Controle e a Redução de Armas e para Segurança Internacional, sendo confirmado para o cargo em maio de 2001 em uma votação apertada no Senado (BLEEK, 2001). Bolton, que posteriormente foi um dos principais representantes dos EUA nas conversações com os russos sobre novas reduções ofensivas estratégicas, já tinha trabalhado no Departamento de Estado durante as administrações Reagan e George H. W. Bush e era um crítico da política do governo Clinton para controle e redução de armas e para não-proliferação, particularmente da defesa do CTBT pela administração democrata. Bolton identificou como grandes metas reduzir o número de armas nucleares nor- 
te-americanas "de forma compatível com a segurança nacional”, reforçando a idéia de que a Rússia também deveria reduzir as suas, e persuadir os membros dos Executivos de outros Estados - em especial da Rússia - a aceitar os planos relacionados à defesa antimísseis norte-americana ${ }^{21}$ (ROUGH..., 2001). Nesse período, o subsecretário apontou que o controle e a redução de armas continuariam a ter prioridade elevada para a administração Bush somente se servissem para a promoção dos interesses norte-americanos. Quando os acordos existentes fossem "contraproducentes ou obsoletos", Bush reveria tais compromissos e consideraria se valeria a pena a busca de novas obrigações. Segundo Bolton, a posição norte-americana sobre controle e redução de armas era fruto de um cálculo custo-benefício e tomava forma de acordo com a consideração dos diferentes instrumentos de política externa. A opção de Bolton por "reduções unilaterais e paralelas" insere-se nessa lógica, pois ele as via como mais flexíveis e "econômicas". Para o subsecretário, ambos os lados não ficariam presos a números artificiais e poderiam decidir por eles mesmos como estruturar forças estratégicas (BOLTON, 2001). A posição de Bolton revela traços de uma perspectiva presente também nas de outros membros da administração Bush, designada por Gottemoeller (2001) como "unilateralismo cooperativo": tais indivíduos sugeriam que as novas reduções ofensivas estratégicas fossem realizadas unilateralmente, mas de forma essencialmente cooperativa. Isso poderia incluir anúncios coordenados sobre reduções ou medidas de transparência durante o processo de implementação.

Formada a coalizão entre os membros da ala menos moderada da administração Bush - com os quais seu estilo político era mais compatível -, esses indivíduos identificaram, a partir da decisão inicial do presidente de que um novo planejamento estratégico era necessário para enfrentar as novas ameaças, a necessidade de conservar a autonomia para modernizar e operar forças estratégicas e táticas contra tais ameaças e, ao mesmo tempo, preservar a capacidade de lidar, em 
uma situação mais remota, com potências como China ou Rússia no caso de reversão da relação cooperativa. Embora Powell e elementos do Departamento de Estado tentassem refrear decisões do presidente que pudessem comprometer a estabilidade estratégica, sua influência sobre as questões de segurança estratégica era gradativamente erodida por Rumsfeld, Rice e outros indivíduos que, ocupando cargos centrais na burocracia norte-americana relacionados à formulação da política de segurança no Departamento de Defesa e no Gabinete presidencial, detinham recursos, informação e apoio presidencial (ALLISON, 1971) necessários à rápida implementação de uma nova orientação dessa política, que estimulasse a pesquisa e o desenvolvimento das opções possíveis de defesas antimísseis, evitasse os entraves colocados por mecanismos jurídicos intrusivos que obstaculizassem a operação dos sistemas nucleares, mantivesse aberta a possibilidade de realização de novos testes para a produção de novas ogivas e solucionasse problemas nos sistemas que já existiam.

A ênfase na flexibilidade na nova postura estratégica foi cristalizada nos documentos emitidos pela administração Bush. A NPR recomendava a substituição gradual da tríade estratégica que vigorara durante a Guerra Fria - composta por ICBMs, mísseis balísticos lançados de submarinos (em inglês, submarine-launched ballistic missiles (SLBMs)) e bombardeiros estratégicos - por um conjunto de opções militares para lidar com novas e antigas contingências. Este conjunto seria composto por capacidades de ataques nucleares e não nucleares, com funções de comando e controle associadas; defesas passivas e ativas, incluindo comando e controle para as aéreas e as antimísseis; e pesquisa, desenvolvimento e infra-estrutura industrial para fabricação e manutenção de sistemas ofensivos e defensivos. A nova tríade incluiria cerca de um terço das ogivas operacionalmente desdobradas $^{22}$ em 2002, uma vez que as reduções fossem completas. O tamanho reduzido dessa força requereria sistemas mais confiáveis. Além dos esforços para a revisão dos antigos, poderia surgir a neces- 
sidade de modificar, modernizar e substituir partes das forças nucleares ou desenvolver sistemas mais adequados às necessidades da nação. A NPR apontava que, apesar de o governo norte-americano tentar manter seu arsenal sem testes nucleares adicionais, isso poderia não ser possível em um futuro incerto. Como os EUA não podiam atingir certos alvos subterrâneos, o documento recomendava que novas capacidades fossem desenvolvidas a fim de destruí-los. Além disso, sugeria a manutenção de ogivas em uma "força de resposta", que poderia ser reposicionada em face de contingências potenciais. Tais ogivas também poderiam oferecer uma reserva a partir da qual as substituições seriam realizadas mais rapidamente (CENTER FOR ARMS CONTROL AND NON-PROLIFERATION, 2002; 2003). Essas decisões comprometiam a entrada do CTBT em vigor, o fortalecimento do ABMT e dos STARTs, a redução de sistemas não estratégicos, a aplicação do princípio da irreversibilidade às medidas de desarmamento e redução nucleares, a reafirmação do objetivo de desarmamento completo sob controle internacional efetivo e o desenvolvimento de capacidades de verificação dos acordos sobre desarmamento nuclear, pontos estabelecidos no plano de ação de 2000.

Para lidar com novos desafios, a NPR recomendava um novo planejamento estratégico das forças norte-americanas, que deixaria para trás uma perspectiva baseada em uma ameaça específica (threat-based approach), como a URSS fora durante a Guerra Fria, e caminharia rumo ao desenvolvimento e ao desdobramento de capacidades para lidar com ameaças imediatas, imprevistas ou potenciais (capabilities-based approach). Livre das limitações e dos excessivos custos políticos de novos acordos complexos, minuciosos e precisos com a Rússia - que, por exemplo, impusessem um grande número de restrições à manutenção, à operação e à modernização de suas forças ofensivas estratégicas (SOKOV, 2002; 2003) -, Bush poderia ajustar forças nucleares sem ser acusado de estar rompendo acordos estabelecidos. Alcançando entendimento com os membros 
do Executivo russo em relação ao ABMT e às "reduções unilaterais cooperativas", acreditava que os EUA e a Rússia poderiam levar o processo de reduções ofensivas estratégicas além do que estava determinado na plataforma do START. Ademais, a construção e o desdobramento de sistemas defensivos, embora imperfeitos em um primeiro momento, poderiam reduzir a atração de Estados-párias por mísseis balísticos. A defesa fortaleceria - e não substituiria - a dissuasão nuclear. Eliminando o peso de acordos e de negociações contraproducentes na sua visão, Rumsfeld e Rice acreditavam que os EUA se encontravam em uma situação mais favorável à construção de um novo paradigma estratégico, que preservaria sua segurança e permitiria que as relações dos EUA e da Rússia fossem "além da Guerra Fria", mostrando aos membros do Executivo russo que as maiores ameaças à segurança norte-americana não advinham mais da Rússia e realizando a preparação para combater novos perigos (CENTER FOR ARMS CONTROL AND NON-PROLIFERATION, 2002; 2003; CIRINCIONE; WOLFSTHAL, 2001).

Reitero minha posição de que a postura estratégica confirmada na NPR fortalece o papel das armas nucleares na política de segurança norte-americana, além de evidenciar a imprecisão sobre uma série de armas que tal administração poderia - e pretendia - desdobrar e desenvolver e sobre as ameaças que deveriam ser enfrentadas - imprecisão essa que poderia justificar a manutenção de muito mais armas nucleares pela necessidade de preservação da sua segurança. Além de sugerir que os EUA poderiam ser os primeiros a utilizar armas atômicas em contingências que envolvessem membros do TNP, a revisão explicitava o apoio da administração Bush à exploração de novas armas nucleares ainda mais potentes e de defesas antimísseis confiáveis, comprovando minha posição de que tal administração não revela um real comprometimento com o desarmamento nuclear efetivo.

Nos EUA, a nova postura estratégica e a posição negociadora inicial sobre temas relacionados a desarmamento nuclear já apontavam 
para o desrespeito e o abandono de pontos do plano de ação de 2000, e o mesmo vinha acontecendo na Rússia. Ao assumir a Presidência da República, Putin concentrou ainda mais poder no Executivo às custas das lideranças regionais e, superando a desorganização institucional da presidência de Boris Yeltsin, "limpou" o Executivo durante seu primeiro mandato, colocando seus indicados políticos nos principais cargos e fortalecendo o controle do Kremlin sobre a política russa (BREMMER; CHARAP, 2006-2007, p. 84). Nesse sentido, embora as preferências, valores e disposições de Putin sejam o principal indicativo dos rumos da política externa e de segurança russa, sua administração herdou nos seus primeiros anos uma série de discussões burocráticas que se desenvolviam desde o fim da década de 1990 acerca do papel das armas nucleares na política de segurança nacional. As reformas militares posteriores ao fim da Guerra Fria eram o principal tema no debate entre os sergeyevistas - aliados do ex-comandante-chefe das Forças de Mísseis Estratégicos e ministro da Defesa Marshal Igor Sergeyev, que defendiam um papel relevante para os sistemas nucleares estratégicos - e os kvashnistas - aliados do ex-chefe do Estado-maior geral e vice de Sergeyev, Anatoly Kvashnin, que desejavam um maior destaque às forças convencionais para lidar com conflitos regionais específicos, como a guerra na Chechênia. Na administração de Yeltsin, Sergeyev conseguiu a aprovação do Conselho de Segurança para a criação de uma Força de Dissuasão Estratégica, que combinaria as capacidades nucleares estratégicas na força de mísseis com as da Marinha e da Força Aérea na forma de um comando estratégico integrado. Já durante a administração Putin, Kvashnin sugeriu que a força de mísseis fosse reduzida a um serviço separado e absorta na Força Aérea, decisão à qual Sergeyev se opôs. Reconhecendo a urgência das questões regionais, $\mathrm{Pu}$ tin pareceu definir a situação em favor de Kvashnin, demitindo generais ligados a Sergeyev, subordinando a Força de Mísseis Estratégicos à Força Aérea e colocando mais ênfase na ampliação do arsenal convencional (GOTTEMOELLER, 2004). 
Embora a vitória de Kvashnin parecesse definitiva e a "desnuclearização" da política militar apontasse para o fim decisivo da manutenção da paridade nuclear com os EUA e sua substituição por uma força nuclear mínima, uma série de preocupações começou a apontar para o reforço do papel das armas nucleares na política de segurança. Na periferia do país, a proliferação de WMD poderia ameaçar o equilíbrio regional, enquanto, nos EUA, pesquisas acerca da defesa antimísseis vinham sendo desenvolvidas. Bush enfatizava que a defesa antimísseis não era destinada a deter o arsenal ofensivo russo, mas a ameaça advinda de Estados-párias. Contudo, os russos destacaram que o programa de pesquisa e de desenvolvimento da administração Bush apontava para sistemas antimísseis mais ambiciosos, que poderiam ameaçar capacidades ofensivas estratégicas russas em um futuro incerto. Tal ameaça indicava que o START II - que ainda não havia entrado em vigor - poderia ser definitivamente abandonado a fim de preservar a flexibilidade russa para conter essas defesas. Em vez de aposentar seus mísseis estratégicos, Putin decidiu que eles continuariam a ser desdobrados por mais uma década. Além disso, também preocupavam os russos as pesquisas nos EUA sobre sistemas atômicos para teatros de operações e a modificação de armas nucleares para a destruição de bunkers (GOTTEMOELLER, 2001; 2004; KUCIA, 2003c). Diante do novo contexto estratégico, membros da administração Putin começavam a falar sobre a necessidade de modernização estratégica, buscando formas de manter uma força nuclear estratégica modernizada e promover melhorias nas forças convencionais em face das dificuldades econômicas. Nesse sentido, Putin e membros de sua equipe viam a necessidade de superar obstáculos políticos e jurídicos à sua flexibilidade estratégica e, assim, fortalecer a autonomia no planejamento militar.

Tais preocupações se materializaram no relatório de outubro de 2003 emitido pelo Ministério da Defesa sobre a modernização das forças estratégicas, que prometia um arsenal renovado de armas nucleares 
baseadas na terra para os trinta anos seguintes e alertava que a doutrina militar russa poderia ser revista se os EUA continuassem apoiando a condução de ações militares preemptivas e estimulassem o desenvolvimento de novas armas nucleares. Respeitando os limites estabelecidos pelos acordos de controle e redução de armas assinados pela Rússia, Putin afirmou na ocasião que substituiria as armas mais antigas pelos mísseis SS-19 armazenados, o que daria à Rússia tempo suficiente para desenvolver "novas armas para o século XXI". O então ministro da Defesa Sergei Ivanov destacou que notava "tentativas de transformar as armas nucleares de instrumentos de dissuasão em armas para teatro de operações" (KUCIA, 2003c), em alusão aos esforços de pesquisa norte-americanos para armas nucleares de baixa potência. Além disso, Ivanov ressaltava a preocupação com o papel nuclear da OTAN, que poderia culminar na reconstrução radical do planejamento militar russo. Tais receios eram alimentados em face da expansão da organização, que pretendia incluir países do Leste Europeu, e do seu auxílio às operações de manutenção da paz no Afeganistão, mantendo sua presença militar próxima às fronteiras russas. Os membros da administração Putin temiam que, com a adesão das repúblicas bálticas à OTAN, armas nucleares pudessem ser colocadas nos territórios desses países. O vice-chefe do Estado-Maior Geral das Forças Armadas Yuri Baluyevsky enfatizava a certeza da Rússia com relação à “orientação anti-russa da OTAN" e aos planos da organização para reduzir as limitações ao uso de armas nucleares (KUCIA, 2003c).

Com relação às ações russas em relação ao plano de ação de 2000, minha posição é a de que, embora membros da administração Putin buscassem demonstrar que procuravam eliminar os resquícios da Guerra Fria na sua interação com os norte-americanos, muitos viam uma licença para a renovação de uma posição cautelosa em relação aos EUA que ainda exigia a preservação de sistemas nucleares para a garantia da segurança. Creio que o fato de os russos se precaverem 
contra possíveis ameaças futuras não necessariamente pressupõe o retorno ao padrão de relacionamento competitivo que existira entre os EUA e a URSS durante a Guerra Fria. Todavia, em um momento em que os russos reforçavam sua confiança nos sistemas atômicos e desprezavam inúmeros pontos estabelecidos no plano de ação de 2000, ainda conservavam barreiras na definição de um relacionamento mais estável com os EUA, já que se tornava cada vez mais difícil estipular e prever os níveis de forças nucleares da Rússia no caso de reversão da relação cooperativa com os norte-americanos. A meu ver, a postura nuclear russa pode até dar sinal verde para as prioridades nacionais definidas por Putin e sua equipe, mas, além de representar um evidente obstáculo no caminho de um efetivo desarmamento nuclear, oferece estímulos para a proliferação e a disseminação de mercados negros de armas atômicas. Estados que se sintam ameaçados pelo poder da Rússia poderão buscar sistemas mais potentes para conter as forças desse país, e armas nucleares armazenadas em instalações russas com vigilância precária desde o fim da Guerra Fria podem ser vendidas ou roubadas por atores não estatais.

Cumpre finalmente destacar que, desde o debate entre sergeyevistas e kvashinistas em torno da relação entre forças nucleares estratégicas e convencionais, não se discutia o papel das armas nucleares não estratégicas. O consenso entre os principais membros da administração Putin de que tal ponto não deveria ser alvo de discussão fora motivado pela crença na utilidade desses sistemas para compensar as ainda evidentes fraquezas do arsenal convencional russo no enfrentamento de novas ameaças, tangenciando os compromissos de redução do papel das armas nucleares nas políticas de segurança. Na doutrina militar anunciada em 2000, a principal inovação era a sugestão de que armas nucleares não estratégicas poderiam ser usadas de forma limitada a fim de conter ataques convencionais, sem dar início ao escalonamento de um uso generalizado de armas nucleares. O novo conceito, na verdade, renovava a missão das forças nucleares de contenção de 
qualquer ataque - nuclear, químico, biológico ou convencional contra o território russo. A noção de que uma "resposta nuclear limitada" poderia ser aplicada para conter o escalonamento de um conflito foi uma mudança com relação à doutrina da era soviética, que enfatizava a inevitabilidade do rápido escalonamento como forma de se conter a posição norte-americana. A incorporação dessa idéia na política nuclear russa apontava que agora era a Rússia quem deveria cogitar a possibilidade do uso limitado de armas nucleares para compensar sua fraqueza contra um determinado agressor regional (GOTTEMOELLER, 2001; 2004).

\section{- Papel das Escolhas Políticas e das Instituições nas Decisões Norte-americanas e Russas}

Enquanto buscava explicitar a necessidade estratégica de defesa do país e seus aliados contra Estados-párias e grupos terroristas no âmbito internacional, Bush procurava simultaneamente consolidar, na arena doméstica, o apoio dos congressistas, particularmente dos senadores, à nova visão estratégica. Os senadores, de acordo com as instituições domésticas norte-americanas, participam do processo de controle de armas ao aprovar ou vetar tratados, adicionar declarações unilaterais e reservas que modificam o efeito legal dos atos internacionais para os EUA, aprovar o orçamento militar da nação e legislar sobre mudanças na organização dos departamentos do Executivo e suas autoridades estatutárias (BARTON; WEILER, 1976, p. 158; SIMS, 2002, p. 68-69). O apoio republicano era fortalecido ao apontar a urgência de uma estrutura estratégica capaz de lidar com novas ameaças. ${ }^{23}$ Contudo, grande parte dos congressistas democratas muitos informados por especialistas e líderes de organizações e centros de pesquisa nacionais e internacionais, como a Arms Control Association e o Carnegie Endowment for International Peace - não 
apenas questionou a urgência e a gravidade da ameaça de mísseis balísticos e a exeqüibilidade de uma defesa antimísseis confiável, mas apontou que a iniciativa de Bush de reduzir somente o número de ogivas nucleares estratégicas operacionalmente desdobradas desrespeitaria compromissos de irreversibilidade das reduções, além de ignorar ogivas nucleares não estratégicas e estimular uma nova corrida armamentista envolvendo a Rússia e a $\mathrm{China}^{24}$ (BOESE, 2001e; BUSH..., 2001).

A denúncia do ABMT pelos EUA não apenas foi apoiada pelos congressistas republicanos, membros das Forças Armadas e setores conservadores da opinião pública, como muitos desses indivíduos e grupos estimularam o presidente a fazê-lo. Por exemplo, nove senadores republicanos - Trent Lott, Jesse Helms, Jon Kyl, Don Nickles, Robert Smith, Larry Craig, James Inhofe, Richard Shelby e Rick Santorum - enviaram uma carta a Bush encorajando o presidente a denunciar o ABMT. Eles defendiam que não seria "plausível" alcançar um entendimento com a Rússia para o teste "completo" da defesa antimísseis e que, ao mesmo tempo, mantivesse o tratado intacto. Tentar oferecer ao ABMT "flexibilidade" daria "vida contínua a um acordo obsoleto", "o obstáculo mais significativo a melhores relações entre os EUA e a Rússia" (BOESE, 2001e), segundo os senadores. Já democratas como os senadores Joseph Biden e Carl Levin disseram que levar adiante o plano da defesa antimísseis poderia dar início a novas corridas armamentistas. Isso geraria, segundo Levin, um "ciclo de ação-reação em termos de tecnologias ofensivas e defensivas" (US..., 2001). Para eles, a defesa antimísseis viria às custas do combate a ameaças mais prováveis. Críticos em organizações não governamentais (ONGs) e centros de pesquisa também indicavam que a denúncia do $\mathrm{ABMT}$ não era necessária nem prudente, tendo em vista o status pouco avançado do programa de tal defesa e a possibilidade expressa por membros do Executivo russo de modificar o tratado a fim de permitir testes (BOESE, 2002a; CIRINCIONE et al., 2002; 
US..., 2001). Bush procurou minimizar as críticas destinando ainda mais verbas para a luta contra o terrorismo e ampliando a cooperação internacional no combate a tal ameaça, considerada um dos principais desafios à América pelos democratas. Como resultado, após os atentados de 11 de setembro, os senadores do partido optaram por não cortar US\$1,3 bilhão destinado à defesa antimísseis, permitindo que o presidente também os utilizasse na guerra contra o terror (BOESE, 2001d).

Minha posição é a de que, com isso, Bush procurava conciliar as pressões domésticas e ampliar o seu poder de barganha no âmbito internacional, demonstrando que os planos de desenvolvimento da defesa antimísseis eram apoiados por amplos setores políticos norte-americanos, mas estavam voltados para a proteção dos EUA e de seus aliados contra as ameaças de Estados-párias, não a Rússia. Além disso, buscava nas negociações persuadir os russos acerca da importância da autonomia para a realização das reduções e a composição das forças ofensivas estratégicas. Bush percebeu que sua agenda de segurança, incluindo a denúncia do ABMT, poderia ser posta em prática mais facilmente com uma relação mais cooperativa com os membros do Executivo russo. Justificando meu ponto de vista, observam-se concessões feitas pelos representantes de cada lado em áreas distintas - porém interligadas - do seu interesse durante a barganha internacional: Bush concordou em negociar reduções ofensivas estratégicas de forma mais densa, não descartando a possibilidade de assinatura de um novo acordo legalmente vinculante que não impusesse inúmeras restrições à articulação de seus sistemas, em face do consentimento - sem, contudo, ter havido efetivo apoio - de Putin à denúncia do ABMT (GOLDGEIER; MCFAUL, 2002). Os norte-americanos conquistavam a liberdade para desdobrar a defesa antimísseis, e os russos viam a possibilidade de que os norte-americanos confirmassem, talvez em um acordo juridicamente vinculante, a intenção de realizar reduções ofensivas estratégicas a 
um nível que Putin e sua equipe fossem economicamente capazes de sustentar. Confirmando-se a ligação entre áreas temáticas na negociação externa (PUTNAM, 1988, p. 446), os norte-americanos também ampliariam a cooperação político-econômica com a Rússia, como explícito na Declaração Conjunta sobre a Nova Relação dos EUA e da Rússia de novembro de $2001^{25}$ (GOTTEMOELLER, 2001; GOLDGEIER; MCFAUL, 2002; HOLUM, 2002).

Putin considerou a decisão de Bush de denunciar o ABMT "equivocada", mas declarou que ela não ameaçava a Rússia nem colocava em risco o futuro das relações dos EUA e da Rússia (BOESE, 2002a; WOOLF, 2002). O presidente russo, que havia recusado insistentes propostas norte-americanas para denúncia conjunta do tratado, garantiu que a decisão não ameaçava a Rússia, pois o país tinha armas capazes de vencer defesas antimísseis. Putin deixou claro que a Rússia consideraria o START II como definitivamente morto quando a denúncia do ABMT fosse efetivada. Segundo Putin, a Rússia adquiriria o direito aos veículos de reentrada múltiplos independentemente direcionáveis (em inglês, multiple independently targetable reentry vehicle (MIRV)) ${ }^{26}$ assim que o ABMT e todas as restrições associadas tivessem sido abolidos. O presidente russo descreveu a lógica por trás da decisão norte-americana como "não-convincente", já que nem os terroristas nem os Estados-párias "têm ou possivelmente teriam mísseis balísticos estratégicos”. Porém, afirmou que a decisão norte-americana não minaria as relações russas com os EUA ou com o Ocidente e enfatizou a importância da construção de uma maior interação entre a Rússia e a OTAN (BOESE, 2002a; US ..., 2001).

O consentimento à denúncia do ABMT pelos EUA e o abandono do START II - uma atitude mais simbólica do que substantiva, já que o tratado nunca entrou em vigor e provavelmente não entraria, tendo em vista que a Rússia ligara seu destino ao do ABMT dois anos antes - revelam, a meu ver, a tentativa de Putin de mediar pressões tanto internacionais como domésticas. Ao deixar de lado o START II, o pre- 
sidente abandonava definitivamente os obstáculos que seriam colocados pelo tratado à manutenção dos ICBMs com múltiplas ogivas, um dos pilares da postura estratégica russa (WOOLF, 2002). Tais armas são ainda consideradas necessárias para a garantia da segurança nacional, em um momento em que as forças convencionais se mostram cada vez mais obsoletas para lidar com desafios relacionados à proliferação de WMDs presentes na periferia do país (GOTTEMOELLER, 2004). Além disso, equipar seus mísseis com múltiplas ogivas poderia se tornar necessário se os mais antigos não perdurassem o tempo planejado, e ICBMs MIRVados eram considerados mais adequados para a penetração de áreas protegidas com defesas antimísseis, necessários no caso de reversão da nova relação com os EUA (PIKAYEV, 2002; SOKOV, 2002; 2003). Reforçando a ênfase nesses sistemas no planejamento militar do país, o presidente também garantia aos membros da Duma e do Conselho da Federação-dotados pelas instituições domésticas russas de poderes de ratificação e veto sobre questões de política externa e segurança nacional-e aos setores mais conservadores das Forças Armadas - temerosos com relação ao desenvolvimento das pesquisas sobre a defesa antimísseis e novos sistemas de armas nos EUA e ao alargamento da OTAN - que as contramedidas russas estavam em pleno funcionamento. Tendo isso em vista, minha posição é a de que Putin atendia aos interesses de grupos políticos domésticos fundamentais ao seu governo, reforçava o status da Rússia como poder nuclear em fóruns políticos globais e garantia a permanência de instrumentos necessários à defesa do país contra o terrorismo, Estados menores possuidores de WMD e grandes potências como os EUA. Porém, sabendo que uma reação mais inflexível à denuncia do ABMT poderia criar impasses no diálogo político geral no âmbito internacional com os EUA, Putin revelou a insatisfação com a decisão norte-americana, mas, como já estava efetivada, apenas afirmou que cabia aos dois lados minimizar as consequiências adversas, evitando o acirramento de tensões com as lideranças da superpotência. 
Quanto às reduções ofensivas estratégicas, o SORT sintetiza, em termos de conteúdo, a maior parte das propostas de Bush; quanto à forma, ele reflete o desejo de Putin e dos senadores norte-americanos por um acordo formal e legalmente vinculante (WOOLF, 2002). Os win-sets (PUTNAM, 1988, p. 435-441) norte-americanos e russos sobrepunham-se na medida em que ambos desejavam a realização de reduções ofensivas estratégicas, mas havia divergências claras. Nas conversações com os norte-americanos, os russos buscavam um acordo legalmente vinculante e que estipulasse reduções reais, irreversíveis e significativas a 1.500 ogivas nucleares estratégicas ou até menos, provesse previsibilidade e transparência e estipulasse regras de contagem e procedimentos densos para verificação. Especialmente com respeito a armas nucleares estratégicas, os russos preferiam perspectivas com um grau mais elevado de obrigação. A confiança excessiva que tinham em armas nucleares a fim de compensar fraquezas no arsenal convencional tornava menos provável que líderes políticos aceitassem medidas tácitas ou que não fossem legalmente vinculantes. Para especialistas, a confiabilidade declinante dos meios técnicos nacionais de verificação fazia com que os russos preferissem provisões mais formais sobre inspeções locais e troca de informação (KARTCHNER; PITMAN, 2002). Putin desejava provisões robustas, que refletissem o equilíbrio entre reduções ofensivas estratégicas e limites sobre defesas antimísseis potencialmente desestabilizadoras (INTERNATIONAL..., 2003). Nas negociações, os russos conseguiram conquistar apenas o acordo legalmente vinculante, o que, para eles, já foi um grande sucesso. O tratado garantia que o compromisso norte-americano de redução de ogivas continuaria a existir mesmo após o fim da administração Bush. Ademais, obter a assinatura de Bush para o tratado foi vital para Putin, um líder pragmático que sabia que um acordo mais formal sobre reduções ofensivas poderia ajudá-lo a lidar com críticos internos de políticas classificadas por alguns como "pró-ocidentais" (WOOLF, 2002). 
Ele e os demais membros do Executivo russo foram para a mesa de negociação sem uma grande alavanca. Previamente, a principal alavanca dos russos a fim de extrair números menores e outras concessões era a habilidade de bloquear emendas ao ABMT que permitiriam o desenvolvimento de defesas antimísseis, mas essa carta evaporou com a denúncia do tratado (HOLUM, 2002; LODGAARD, 2003; QUINTELLA, 2002). Cientes da grave crise sociopolítica e econômica que atingiu seu país e da importância do apoio norte-americano para reverter tal situação, ${ }^{27}$ os russos fizeram inúmeras concessões, tendo em vista que, se aceitassem o conteúdo proposto pelos norte-americanos, estes não só se comprometeriam a realizar reduções a um nível que os russos eram economicamente capazes de sustentar (HOLUM, 2002), como também ampliariam a cooperação política, militar e econômica, iniciativa prevista na Declaração Conjunta sobre a Nova Relação Estratégica ${ }^{28}$ que complementou o SORT. Tal documento previa iniciativas importantes para os russos, que se mostravam cientes da relevância do apoio norte-americano para a promoção da modernização socioeconômica do país e para a ampliação da sua participação em fóruns políticos globais e regionais (KUCHINS, 2002).

Os russos não convenceram os norte-americanos a adotar regras de contagem do START I, a eliminar veículos de lançamento e ogivas excedentes e a incluir no tratado uma declaração de que a defesa antimísseis norte-americana não minaria a capacidade de dissuasão russa. Embora se tivesse mostrado aberto às várias modalidades de acordo, Bush procurou evitar um legalmente vinculante no perfil daqueles da Guerra Fria. Não desejava quaisquer limites rígidos sobre veículos de lançamento, ogivas armazenadas e defesa antimísseis, ${ }^{29}$ apontando o objetivo de reduzir ogivas nucleares estratégicas operacionalmente desdobradas, disponíveis para uso imediato, a 1.700-2.200, e afirmando que tal flexibilidade seria indesejável para os russos apenas em um contexto de relações hostis entre os dois 


\section{Estados (CENTER FOR ARMS CONTROL AND} NON-PROLIFERATION, 2002; 2003). Bush tentava, assim, reestruturar o jogo e alterar visões dos russos sobre os benefícios dos entendimentos propostos (PUTNAM, 1988, p. 452-456). A iniciativa de Bush de reduzir somente as ogivas nucleares estratégicas operacionalmente desdobradas apontava para o fato de que milhares delas poderiam ser armazenadas. Com isso, ele estaria desrespeitando compromissos previamente estabelecidos de irreversibilidade das reduções e ignorando completamente o número crescente de ogivas nucleares não estratégicas (KIMBALL, 2001; KRISTENSEN, 2001).

Bush aquiesceu aos desejos de Putin por um acordo juridicamente vinculante, pois, ao se manter firme nas suas posições e conduzir o win-set para mais próximo de seu ponto ideal no que dizia respeito ao conteúdo do acordo (MILNER, 1997), garantiu que o tratado refletiria o objetivo de maximização da flexibilidade para definir o tamanho e a estrutura de suas forças ofensivas estratégicas em resposta às novas ameaças. Além disso, lutando para tornarem-se os votantes medianos, os senadores pressionaram para que se concluísse um tratado, que, de acordo com as instituições norte-americanas, precisaria do consentimento de pelo menos dois terços dos senadores presentes para a ratificação e que poderia estar sujeito a emendas, limitando a autonomia do Executivo. Os senadores Biden e Helms pressionaram membros da administração Bush para que o eventual acordo fosse transmitido para o conselho e consentimento do Senado para ratificação como um tratado, demonstrando que tanto membros do Partido Democrata como do Republicano defendiam as prerrogativas constitucionais do Senado e apoiavam o seu papel de oferecer conselho e consentimento para a ratificação dos tratados, ${ }^{30}$ além de buscarem ter um papel mais substantivo nos processos que poderiam alterar o desdobramento das forças estratégicas. As preferências dos senadores norte-americanos quanto à forma do acordo - independentemen- 
te de considerarmos como votante mediano um democrata ou um republicano - aproximavam-se claramente daquelas dos membros do Executivo russo em um aspecto específico: tais indivíduos preferiam que o acordo fosse legalmente vinculante, com um grau elevado de obrigação (ABBOTT et al., 2000). Finalmente, a concessão norte-americana permitia fortalecer a habilidade de Putin de cooperar com os EUA. Ao assinar o tratado, Bush recompensou Putin por sua cooperação e permitiu a ele responder aos críticos com um marco no controle e na redução de armas. Ao assinar o SORT, Putin admitiu a asserção da equipe de Bush de que as questões sobre armas ofensivas e defensivas não deveriam interferir de forma negativa na consolidação da nova relação estratégica dos EUA e da Rússia mais abrangente (KUCHINS, 2002). Os críticos apontavam que a única concessão dos membros da administração Bush foi aceitar um acordo legalmente vinculante, pois, em relação ao conteúdo, Putin aceitou o que os membros do Executivo dos EUA tinham a oferecer, já que acreditava que o futuro da Rússia estava ligado ao Ocidente e não deixaria que um acordo sobre reduções ofensivas estratégicas se colocasse no caminho (US-RUSSIA..., 2002).

Apesar de terem cedido aos desejos de Putin e dos senadores democratas e republicanos por um acordo formal legalmente vinculante, Bush garantiu que o conteúdo do SORT - tratado pouco preciso, detalhado e completo, com provisões bastante maleáveis - refletiria seu objetivo de maximizar a flexibilidade na estruturação de forças, também compartilhado pelos membros do Partido Republicano no Senado. Na arena doméstica norte-americana, Bush e membros da sua equipe anteciparam adequadamente as reações dos senadores às propostas negociadas internacionalmente. ${ }^{31}$ Em um momento em que os russos aceitaram o conteúdo sugerido por Bush para as reduções ofensivas estratégicas, os senadores dos EUA apenas inseriram alguns elementos modestos na resolução de ratificação e não modificaram substancialmente o SORT: as condições e as declarações inse- 
ridas permitiam pelo menos encorajar a prestação de contas e a consulta do presidente norte-americano aos senadores. Assim, evitavam correr o risco de que mudanças amplas não fossem aceitas por Bush nem pelo Executivo e pelo Parlamento russos e assim pudessem comprometer o tratado e a coordenação crescente entre as partes. Os republicanos e alguns democratas ofereceram consentimento para a ratificação do tratado porque acreditavam que ele permitia maximizar a flexibilidade estratégica para atender às contingências imediatas, imprevistas ou potenciais. Embora criticasse a possibilidade de retenção de várias ogivas nucleares estratégicas na "força de resposta", a falta de procedimentos para eliminação de ogivas, a inexistência de um cronograma para as reduções e a ausência de provisões próprias para verificação (BOESE, 2002b), a maior parte dos democratas ofereceu consentimento para a ratificação do SORT porque via que o tratado apenas oferecia uma plataforma inicial para acordos mais substantivos (DAVIS, 2002; KUCIA, 2003a; 2003b). O Comitê de Relações Exteriores não recomendou emendas ao tratado, e, após dois dias de debate nos quais alguns democratas tentaram utilizar seu poder de emenda à resolução de ratificação e as emendas foram retiradas ou rejeitadas, a resolução de conselho e consentimento para a ratificação do tratado foi aprovada unanimemente em março de 2003.

No Legislativo russo, o processo foi mais intricado. O Comitê de Defesa da câmara baixa do Parlamento russo rejeitou o documento de ratificação submetido por Putin, afirmando que não havia procedimentos amplos para verificação. Em fevereiro de 2003, a Duma enviou o documento de volta ao presidente com condições. Ela estipulou que o desdobramento de uma defesa antimísseis pelos EUA, que ameaçasse a capacidade de dissuasão russa, poderia levar à denúncia do tratado. A Duma também requereu: 1) verbas adicionais para garantir que as forças nucleares estratégicas fossem mantidas em níveis compatíveis com as necessidades de segurança nacional; 2) um rela- 
tório do presidente sobre o desdobramento de tais forças; e 3) a participação parlamentar em planos de desenvolvimento, modernização e desmantelamento de armas (KUCIA, 2003a). Em março de 2003, uma semana antes do início da Operação "Liberdade para o Iraque", o Comitê de Defesa da Duma recomendou a aceitação do tratado até o fim do mês. Porém, pouco depois, em face da então iminente ação norte-americana no Iraque, o Conselho da câmara baixa do Parlamento russo, responsável pela agenda legislativa, decidiu adiar a votação do SORT, pelo menos até que a situação no Iraque se normalizasse. Em maio, a Duma retomou a questão e, em um debate acalorado, votou a favor de uma lei federal sobre a ratificação do SORT. Ela identifica dois cenários possíveis em que a Rússia deveria denunciar o tratado: a ampliação significativa das forças ofensivas estratégicas de alguma nação ou grupo de nações e o desdobramento, por outro Estado ou grupo de Estados, de um sistema de defesa antimísseis capaz de reduzir significativamente a eficiência do arsenal nuclear russo (FEDERAÇÃ̃ RUSSA. Ministério das Relações Exteriores, 2003; DUMA..., 2003; MOSCOW..., 2003; INTERNATIONAL..., 2003).

Pouco antes da votação, a Duma ouviu Putin, que afirmou que as provisões do tratado permitiriam aos russos manter suas forças estratégicas em um nível adequado, de acordo com as capacidades econômicas do país e com a dinâmica da política e das atividades militares no mundo contemporâneo. Após a votação, os comunistas mostraram-se desapontados, prevendo um "declínio catastrófico da segurança russa" e afirmando que o tratado era "um presente para Bush". A câmara alta do Parlamento russo, isto é, o Conselho da Federação, aprovou o SORT em maio de 2003, por 145 votos a 5. Segundo o presidente do Comitê de Relações Exteriores do Conselho, Mikhail Margelov, a entrada do tratado em vigor cobriria um "vácuo legal na esfera da estabilidade estratégica", criado pela denúncia do ABMT e pelo colapso do START II. Como analistas previam, nem a Duma 
nem o Conselho da Federação desafiaram Putin - que tinha apoio bem maior dessas instituições que Yeltsin - ao ameaçar a rejeição do tratado. Embora as lideranças do Partido Comunista tivessem classificado o SORT como "uma traição aos interesses russos", a maior parte dos membros das duas câmaras congratulou Putin por ter convencido Bush a assinar um acordo legalmente vinculante (PODVIG, 2002; POWELL; IVANOV, 2003; WOOLF, 2002).

Os norte-americanos não tinham muito interesse em um diálogo denso sobre tais armas pós-SORT, pois já tinham conquistado aquilo que desejavam de Moscou, de forma que não havia sentido em fazer mais concessões. Ademais, os russos não estavam prontos para colocar novas cartas diplomáticas, como as armas não estratégicas, em uma mesa de negociação, já que seus estabelecimentos político e militar não tinham desenvolvido uma doutrina coerente definindo missões específicas e cenários para o uso desses sistemas (PIKAYEV, 2002; SOKOV, 2002; 2003). Ademais, militares russos declararam que quaisquer reduções abaixo dos níveis do SORT requereriam a participação de outros Estados que tivessem armas nucleares. Reduções ainda mais amplas poderiam deixar a Rússia em uma situação em que seus líderes não mais se mantivessem tão indiferentes aos arsenais do Reino Unido, da França e da China (SOKOV, 2003). Os representantes de cada país provavelmente se limitariam mais ao "mínimo denominador comum", o que, do meu ponto de vista, poderia não trazer qualquer progresso efetivo quanto ao desarmamento nuclear. Putin não desejava que um acordo sobre reduções ofensivas estratégicas atrapalhasse o curso da coordenação político-econômica com os EUA. Bush, por sua vez, não queria que se impusessem limitações à sua liberdade de ação para combater novas ameaças, dando a entender que a política nuclear norte-americana para a Rússia parecia muito mais o resultado de decisões tomadas a fim de enfrentar novos problemas - como os Estados-párias e as organizações terroristas - do que a própria Rússia. Porém, penso que a 
previsibilidade com relação aos níveis das armas nucleares mais poderosas no arsenal de ambos os países era excessivamente limitada com um acordo tão flexível, podendo, assim, acarretar riscos no caso de uma mudança dos rumos da cooperação entre essas potências.

As lideranças norte-americanas negligenciaram ou abandonaram os compromissos sobre desarmamento nuclear assumidos no plano de ação de 2000 com o objetivo de manter abertas suas opções não apenas de desdobramento de armas nucleares, mas também de pesquisa, produção e teste dessas armas. Apesar de reforçar que não tem o objetivo de retomar os testes nucleares, Bush recusou-se a submeter o CTBT para a reconsideração do Senado, além de buscar a melhoria das condições preparatórias de testes (YOST, 2005, p. 97). Enquanto os democratas e líderes de ONGs ressaltavam que a preservação da infra-estrutura de testes ampliava a possibilidade de acidente nuclear e poderia ser usada por outros Estados para justificar a aquisição e a modernização de capacidades nucleares, membros do Pentágono determinados a obter autorização para pesquisa sobre perfuradores nucleares, o que envolveria testes para modificação de bombas - e parte dos congressistas republicanos defendiam a prontidão para a realização de testes em face da possível necessidade de se fabricarem novos designs de ogivas de baixa potência e de sanar deficiências nos sistemas existentes em resposta às novas ameaças enfrentadas pelos EUA. Bush buscava persuadir os críticos de que havia a necessidade de convencer Estados-párias e organizações terroristas de que os EUA usariam suas armas nucleares se houvesse necessidade; na falta de armas nucleares menores ou modificadas, os inimigos poderiam alimentar a dúvida sobre a disposição dos formuladores de decisão norte-americanos de conduzirem um ataque nuclear. Assim, segundo Bush e representantes dos Departamentos de Estado e de Defesa, os esforços de modernização nuclear poderiam fortalecer a dissuasão ao alterar a percepção do adversário acerca daquilo que os EUA fariam ou estariam preparados para fazer em uma crise. 
Tendo o poder de aprovar o orçamento da nação, o Congresso norte-americano - controlado pelos republicanos nessa época - cortou, em 2004, fundos para a exploração de tipos novos e modificados de armas nucleares pelo Departamento de Energia, destinando parte das verbas para ampliar a confiabilidade das ogivas existentes. Além disso, limitou verbas destinadas à construção de uma instalação para a produção de núcleos de armas nucleares e programas voltados para a redução do tempo necessário à preparação de um teste nuclear. $\mathrm{Na}$ verdade, os congressistas do Partido Republicano mostravam-se divididos quanto ao tema. O senador John Warner, líder do Comitê de Forças Armadas do Senado, destacava que tanto o perfurador nuclear como os programas de substituição de ogivas eram "essenciais, prudentes e necessários". Já o representante David Hobson, líder do Subcomitê de Apropriações, Energia, Recursos Hídricos e Desenvolvimento na Câmara dos Representantes, liderou o Congresso no veto ao pedido de US\$27,6 milhões de dólares para o perfurador nuclear, sob a justificativa de que o programa não era "cientificamente possível" (BOESE, 2004a; 2005b). Pouco tempo depois, o Congresso reduziu a contribuição norte-americana à organização do CTBT, que compõe quase um quarto do orçamento dessa instituição. A então secretária de Estado Condoleezza Rice justificou os cortes pelas restrições fiscais e não pela oposição norte-americana à missão da organização (KIMBALL, 2005b).

Nas negociações no âmbito internacional, o diretor-geral da AIEA, Mohamed ElBaradei, e lideranças de Estados como Canadá e de membros da União Européia e do Movimento Não-Alinhado criticavam a noção de que era moralmente repreensível que alguns Estados buscassem WMD, enquanto outros países continuavam confiando nesses sistemas para a garantia da segurança, refinando suas capacidades, postulando planos para o seu uso e, com isso, minando a credibilidade do regime de não-proliferação nuclear e podendo dar origem a uma nova corrida armamentista. Embora buscasse reafirmar 
os laços de cooperação com os EUA, Putin alertava que, conforme os norte-americanos ampliassem a qualidade de suas armas e seu potencial militar, a Rússia precisaria garantir uma nova geração de armas e tecnologia (BOESE, 2005b). Apesar de Estados signatários do CTBT terem dado passos significativos rumo ao preenchimento dos requisitos para a entrada do tratado em vigor e a Comissão Preparatória da Organização do CTBT tenha avançado na definição de um sistema denso de verificação, pouco pôde ser feito para que Bush modificasse sua posição com relação ao tratado, principalmente diante do interesse do presidente em preservar a flexibilidade estratégica para lidar com os principais desafios à segurança norte-americana. Grande parte da comunidade internacional recebeu bem a moratória voluntária com relação aos testes, mas reiterava que isso não deveria funcionar como um substituto da entrada de um tratado juridicamente vinculante em vigor (KIMBALL, 2005b).

Com relação à produção de material físsil, após a revisão interagências de 2003 - que levou à rejeição norte-americana ao compromisso de verificação do Mandato Shannon, adotado por consenso na Conferência sobre Desarmamento em 1995 estipulando negociações de um FMCT não discriminatório, multilateral e efetivamente verificável -, uma série de impasses foi colocada pelos EUA nessa Conferência. Embora Bush reafirmasse o compromisso de negociar um tratado visando a proibição da produção de urânio altamente enriquecido e plutônio para propósitos militares, sua nova postura contrasta radicalmente com as propostas do presidente Bill Clinton de promoção de um acordo com mecanismos densos de inspeção: ao contrário de Clinton, Bush apontava que o acordo exigiria um regime de verificação tão intrusivo que não era "realisticamente possível". Tal posicionamento colocava os EUA e alguns de seus principais aliados em campos opostos - tendo em vista que Austrália, Canadá e Japão apoiavam o Mandato Shannon -, inserindo ainda mais obstáculos ao andamento das negociações no âmbito da Conferência e ques- 
tionando, inclusive, sua relevância como um corpo de negociação. Antes desse impasse, representantes de países como a China e a Rússia apoiavam negociações sobre desarmamento nuclear e prevenção da corrida armamentista no espaço cósmico em paralelo às negociações do FMCT - em parte em virtude da preocupação com o desenvolvimento da defesa antimísseis norte-americana, que poderia incluir sistemas baseados no espaço. Já os norte-americanos defendiam que as negociações do FMCT deveriam ter um mandato claro que não estivesse ligado a "outras propostas não relacionadas", nas palavras da embaixadora norte-americana na Conferência, Jackie W. Sanders (BOESE, 2004b; KIMBALL, 2004; PREEZ, 2005).

A mudança de posição norte-americana com relação à verificação no âmbito do FMCT reflete os interesses dos principais representantes da administração Bush em impedir o acesso de inspetores internacionais - com autoridade política e legal para visitar locações suspeitas e detectar possíveis violações - a suas instalações envolvidas na geração de combustível nuclear para reatores de propulsão naval. Com isso, Bush procurava atender aos interesses de grupos internos, mais especificamente de membros do Departamento de Defesa e das Forças Armadas que resistiam ao FMCT. Tais grupos tinham o objetivo de proteger informações relacionadas aos programas da Marinha que visam gerar urânio altamente enriquecido para embarcações movidas à energia nuclear. Mecanismos robustos de verificação destinados a ampliar a aquiescência a acordos internacionais de controle de armas impõem limites à flexibilidade estratégica norte-americana. Além disso, um regime robusto de verificação prolongaria as negociações por anos, permitindo que países que produzem material físsil sem qualquer limitação continuassem a fazê-lo durante esse tempo. Enquanto procurava atender às demandas domésticas, Bush também buscava conciliar interesses internacionais em áreas temáticas distintas, porém relacionadas: a forte relação estratégica da administração Bush com a Índia e o Paquistão - que, segundo suspeitas, produ- 
zem material físsil para fins militares - na luta contra o terrorismo conduz a uma mudança de seu pensamento com relação a um dos principais objetivos do FMCT - impedir uma corrida armamentista no Sul da Ásia. Tal mudança revela que, como a Índia e o Paquistão não parecem desejar desistir de seus programas nucleares em um futuro próximo, o principal objetivo dos norte-americanos deixa de ser o impedimento de aquisição de armas nucleares por tais países e passa a ser a ampliação da cooperação com eles, visando impedir a proliferação de tecnologia nuclear para Estados-párias e atores não-estatais (BOESE, 2004b; KIMBALL, 2004; PREEZ, 2005).

\section{Considerações Finais}

Muitos Estados não detentores de armas nucleares criticam as potências atômicas - principalmente as duas maiores - por terem negligenciado ou abandonado os compromissos sobre desarmamento assumidos na Conferência de Revisão do TNP em 2000. Alega-se que, se os objetivos de não-proliferação do Tratado devem ser sustentados por medidas mais rígidas de verificação e de enforcement, o mesmo deveria ocorrer com os objetivos de desarmamento (PREEZ, 2005). O descaso revelado pelas grandes potências em relação aos pontos do plano justifica em parte o fracasso da sétima Conferência de Revisão do TNP em 2005, na qual os EUA fizeram uma ampla exposição de suas conquistas no campo da não-proliferação, mas se recusaram a autorizar que a agenda mencionasse o consenso da Conferência de 2000 como base para a revisão e a avaliação do progresso do Tratado em 2005 (JOHNSON, 2005).

Confirmando-se a correção das hipóteses desta pesquisa, os membros dos Executivos desses países - apoiados, na maioria dos casos, por grande parte dos membros dos Legislativos e dos principais grupos de interesse envolvidos, como as Forças Armadas - procuraram garantir autonomia para definir a estrutura e a composição de forças estratégicas e táticas, modernizar arsenais atômicos e operar uma 
força capaz de lidar com contingências que envolvam não apenas potências nucleares tradicionais, mas principalmente novos Estados detentores de armas de destruição em massa e organizações terroristas. Embora especialistas se refiram a tal busca por autonomia como uma "nova era de desarmamento nuclear" ou de "controle de armas por outros meios" (LARSEN, 2005), a não-implementação total e efetiva do plano de ação de treze pontos práticos sobre desarmamento nuclear pode estimular o desenvolvimento de armas nucleares por outros Estados e reduzir a previsibilidade na relação estratégica entre as duas maiores potências atômicas.

\section{Notas}

1. No artigo VI do TNP, as partes - entre elas, as cinco potências detentoras dos maiores arsenais atômicos em âmbito mundial - comprometeram-se a negociar medidas efetivas relacionadas à eliminação da corrida armamentista e ao desarmamento nuclear, reduzindo os incentivos para a aquisição desses sistemas. Na quinta Conferência de Revisão do TNP em 1995 - a primeira após o fim da Guerra Fria -, a reafirmação das obrigações de desarmamento pelos Estados Unidos da América (EUA), Rússia, Reino Unido, França e China foi essencial para que o Tratado fosse prorrogado por tempo indeterminado (KIMBALL, 2005a; RAUF, 2001, p. 12).

2. O termo "desdobramento" - do inglês "deployment" - refere-se à colocação de armas, pessoal ou equipamento em posição de prontidão para combate (JESUS, 2005, p. 183).

3. Bush alegava que o Tratado permitiria a retenção de estoques existentes de material físsil e a produção contínua para fins pacíficos; assim, os inspetores teriam dificuldades em determinar o propósito do material produzido e em indicar se ele foi fabricado antes ou depois da entrada do tratado em vigor (BOESE, 2005a).

4. Destaca-se o desenvolvimento de uma versão móvel do míssil balístico Topol-M e de um novo míssil balístico lançado de submarinos, o Bulava, a fim de modernizar suas forças de mísseis de longo alcance. O comandante-chefe da Força Aérea, Vladimir Mikhailov, anunciou em 2002 planos de modernização 


\section{Diego Santos Vieira de Jesus}

de caças que carregam armas nucleares, e a produção em pequena escala do bombardeiro Blackjack foi reiniciada em 2004 (NORRIS; KRISTENSEN, 2004; 2005).

5. Parte dos especialistas (PAYNE, 2005; LARSEN, 2005) destacava que a inclusão do amplo espectro de capacidades militares na NPR permitia a preservação da segurança nacional enquanto o número de ogivas estratégicas fosse reduzido e oferecia flexibilidade para lidar com um ambiente marcado pela imprevisibilidade de novos oponentes potenciais (ELLIS, 2003, p. 126-131). Porém, segundo críticos, é significativa a contradição entre a retórica norte-americana e suas ações: como grande parte das ogivas nucleares removidas não seria destruída, o número total desses sistemas no arsenal ativo poderia manter-se inalterado, enquanto forças convencionais e defesas ativas e passivas complementavam - e não substituíam - tais sistemas. Documentos como a NPR e a Diretiva Presidencial sobre Segurança Nacional 17 estariam apagando a distinção operacional entre sistemas convencionais e nucleares, já que o objetivo dos últimos não parecia mais ser a dissuasão pela ameaça de retaliação, mas a destruição de alvos nos campos de batalha (HUNTLEY, 2006, p. 50-53; KRISTENSEN, 2005). Ao caminharem rumo ao desdobramento de capacidades para lidar com quaisquer ameaças, os EUA poderiam se aproveitar da falta de definição de um inimigo específico para manter um número de armas nucleares maior que o necessário (HALPERIN et al., 2002; MENDELSOHN, 2002). Preservar a confiança nas armas nucleares também minaria esforços de não-proliferação ao sugerir a outros Estados que as armas nucleares são necessárias à sua segurança (BLEEK, 2002a; KIMBALL, 2005a; PREEZ, 2002).

6. Argumentos críticos à denúncia do ABMT pelos EUA apontavam que Estados-párias poderiam ter outros métodos de ataque que não podem ser contidos pela defesa antimísseis - como armas químicas e biológicas (CIRINCIONE et al., 2002) - e os custos do desenvolvimento desse sistema eram elevados, apesar de tal sistema não ser tecnicamente capaz de interceptar de forma efetiva mísseis balísticos (WOLFSTHAL et al., 2001). Se, no futuro, os EUA conseguissem desenvolver um sistema antimísseis efetivo, a Rússia - livre dos compromissos do START II - e a China poderiam desenvolver armas mais poderosas que não pudessem ser interceptadas, no caso de reversão da cooperação com os EUA (FUERTH, 2001, p. 103-105; GLASER; FETTER, 2001, p. 43-44; NEWHOUSE, 2001, p. 97; SOKOV, 2001). Para outros autores (WALLER, 2001; PAYNE, 2005), embora não pudesse conter todas as ameaças aos EUA, a defesa antimísseis garantiria a proteção contra mísseis de Estados-párias, e a defesa menos custosa e mais avançada tecnologicamente não poderia ser desenvolvida dentro das limitações do ABMT, visto como "um resquício da Guerra Fria”. Mesmo que Rússia e China não concordassem com a denúncia pelos EUA, era improvável a reversão da cooperação com esse país, porque precisa- 
vam da ajuda norte-americana no combate à proliferação e ao terrorismo, na ampliação da participação em fóruns políticos e na promoção da modernização socioeconômica (LIEVEN, 2002, p. 256-257; RUMER; WALLANDER, 2003-2004, p. 69-70).

7. O principal mérito do tratado, segundo especialistas (SMITH, 2004; MILLER et al., 2002), era a conclusão lógica da confrontação entre as superpotências da Guerra Fria: tais países não precisavam de novos acordos extensos que impusessem restrições robustas à manutenção de arsenais. Arranjos menos precisos - sem mecanismos densos de verificação que limitassem a flexibilidade estratégica - pareciam necessários para acomodar a nova agenda de segurança (LARSEN, 2002, p. 10). Alguns estudiosos entendiam que o SORT trazia um enfoque inovador nas ogivas em vez dos vetores (SOKOV, 2002) e que nem a Rússia nem os EUA estariam dispostos a conduzir negociações longas e custosas de outro acordo como o START I (GOTTEMOELLER, 2002), mas criticaram o otimismo acerca da "flexibilidade ilimitada" (O’HANLON, 2002; BUKHARIN; DOYLE, 2002). Embora o SORT simbolizasse uma reversão do unilateralismo da administração Bush para controle de armas, ele ignorava ganhos possíveis do START II (HOLUM, 2002). Os críticos mais severos viam que o armazenamento de ogivas excedentes criaria riscos, pois poderiam ser roubadas, e que o SORT sequer mencionava reduções não estratégicas (WOOLF, 2002), sendo pouco mais que um "acordo de cavalheiros", que tinha menos a ver com desarmamento efetivo do que com preservação da flexibilidade (KIMBALL, 2002; DAALDER; LINDSAY, 2002). Após o tratado, era provável que cada lado evitasse discussões sobre mais reduções, pois sabia que o debate sobre questões sensíveis poderia criar impasses no diálogo político geral (PIKAYEV, 2002; SOKOV, 2002; 2003).

8. Sokov $(2002 ; 2003)$ destaca que setores militares pressionaram o Executivo a desenvolver novos sistemas, pois, além de os antigos sistemas estarem sucateando-se, eram necessárias armas modernas para penetrar áreas protegidas com defesas antimísseis em caso de reversão da cooperação com os EUA. Segundo Gottemoeller (2004), Putin considerou a necessidade de lidar com organizações terroristas e Estados-párias na sua periferia e a "expressão política de orgulho nacional" diante do eleitorado. Apesar de integrarem aspectos diversificados, tais explicações desprezam reações internacionais à decisão de Putin e respostas oferecidas a tais desenvolvimentos. A principal negligência ocorre com relação às condições sob as quais elementos como "orgulho nacional" podem influenciar a decisão política.

9. O primeiro termo refere-se a Marshal Igor Sergeyev, antigo comandante-chefe das Forças de Mísseis Estratégicos e ex-ministro da Defesa russo, que defendia um forte papel das armas nucleares na política militar russa. O segun- 


\section{Diego Santos Vieira de Jesus}

do remete a Anatoly Kvashnin, ex-chefe do Estado-maior geral e vice de Sergeyev, que desejava que o Kremlin colocasse mais ênfase no fortalecimento das Forças Armadas convencionais para lidar com conflitos regionais (GOTTEMOELLER, 2004).

10. De acordo com a conjectura de Schelling (apud PUTNAM, 1988, p. 440), as divisões internas em um país criam vantagens na barganha internacional: se um negociador se encontra em uma situação doméstica em que um grupo se opõe fortemente a certas concessões, ele pode evitar condescender nesta área e garantir um melhor acordo internacionalmente. Já Milner (1997, p. 235) aponta que, quanto mais houver divisões internas, menos provável é a cooperação internacional, pois o Executivo terá mais dificuldade de obter o consentimento para ratificação e será forçado a negociar acordos que atendam às preferências de outros atores domésticos.

11. São levados em conta o custo do não-acordo - quanto menor tal custo, menor o win-set -, a existência de homogeneidade entre escolhas domésticas e a possibilidade de ligação sinérgica entre áreas temáticas no Nível I, que pode alterar resultados no II.

12. Incapacidade de cumprir uma promessa por não se obter consentimento para ratificação.

13. Segundo Milner (1997, p. 15), há uma distinção entre interesses e preferências dos atores. Os interesses representam seus objetivos fundamentais, que mudam pouco e não se distinguem entre atores políticos e econômicos; nesse caso, o interesse central é a maximização de ganhos. Já as preferências se referem a escolhas políticas específicas visando tal maximização, podendo variar de ator para ator de acordo com sua posição política e sua afiliação partidária, por exemplo.

14. A incerteza e a falta de conhecimento do Legislativo podem fazer com que acordos benéficos sejam rejeitados. Porém, um Executivo que tenha informação confidencial pode atingir resultados mais próximos às suas escolhas (MILNER, 1997, p. 20-22).

15. Não pretendo verificar os efeitos da variação na distribuição de informação. Ao longo de toda a análise, será mantida a suposição de informação distribuída de forma assimétrica.

16. Tais princípios estão abrigados no individualismo metodológico e se apóiam na premissa, de inspiração utilitarista, segundo a qual os atores têm comportamento estratégico, ou seja, agem racionalmente movidos por interesse e consideram a interdependência das decisões individuais na escolha da ação que irão praticar (ALMEIDA, 1989, p. 9-10; DUTTA, 1999, p. 4-5). 
17. Os atores selecionados devem obedecer a pelo menos um destes quesitos: Nos Executivos nacionais ou estrangeiros: a) ocupação de cargos de chefe de Estado e membros da equipe de política externa e segurança nacional (vice-chefe, funcionários responsáveis pelas pastas de Defesa e Relações Exteriores, assessores para assuntos militares); b) liderança de grupos de negociadores nas conversações sobre questões relacionadas ao plano de ação.

No Legislativo: a) composição de comitês legislativos de Relações Exteriores ou Forças Armadas, responsáveis pela avaliação de atos internacionais relacionados a sistemas nucleares; b) proposição de emendas aos atos firmados pelo Executivo e reservas, declarações e entendimentos às resoluções de consentimento para a ratificação.

Nos grupos de interesse: a) liderança de grupos de pressão que, ao mobilizarem eleitores e recursos, afetam escolhas políticas de membros do Executivo e Legislativo sobre pontos do plano; b) liderança de organizações consultadas pelos legisladores na obtenção de informação acerca do plano.

18. Ver também Gottemoeller (2001), Goldgeier e McFaul (2002) e Jishe (2001).

19. Cabe lembrar que Rumsfeld presidira a Comissão para a Avaliação da Ameaça de Mísseis Balísticos aos EUA. Tal comissão publicou um relatório em 1998 alertando que as ameaças de mísseis balísticos de longo alcance contra os EUA estavam "mais maduras" e se desenvolviam mais rapidamente do que a Inteligência estimava. O secretário de Defesa classificou a proliferação de WMD e dos sistemas de lançamento como um sério problema, mas enfatizou que essa ameaça seria vencida e garantiu que a defesa antimísseis teria prioridade nos orçamentos futuros do Pentágono (BOESE, 2001a).

20. Segundo especialistas, a nova NPR provavelmente se basearia nas conclusões de um relatório de janeiro de 2001 do Instituto Nacional para Política Pública (em inglês, National Institute for Public Policy (NIPP)), assinado por Keith Payne, co-autor de um ensaio infamante da década de 1980 sobre a política nuclear norte-americana, cujo título era “A vitória é possível”. Entre os participantes de tal estudo, estava Steven Hadley, participante do Conselho de Segurança Nacional. A idéia central do relatório era a de que, em uma era de incerteza estratégica, os EUA precisariam de "flexibilidade" para reduzir ou reconstituir suas forças nucleares de acordo com as circunstâncias, idealmente sem os limites impostos por acordos tradicionais sobre o controle e a redução de armas. Parte dessa "flexibilidade" incluía o desenvolvimento de "papéis futuros" para armas nucleares. Elas seriam empregadas para deter nações cujos líderes desejassem conduzir um ataque contra os EUA com armas químicas e biológicas; limitar baixas norte-americanas em um conflito convencional de grandes propor- 


\section{Diego Santos Vieira de Jesus}

ções; e atender a "necessidades especiais de ataque", como atingir instalações de comando subterrâneas (KERREY; HARTUNG, 2001).

21. A escolha de Bolton para o posto mais importante da administração especificamente destinado à formulação da política sobre controle e redução de armas foi aprovada por todos os senadores republicanos, mas criticada pela maior parte dos democratas. Segundo o senador Joseph Biden, a "retórica inflamada" de Bolton fez com que o senador duvidasse da capacidade do subsecretário de exercer a função. O congressista também destacou que sempre votou contra indivíduos "que se opuseram ao propósito declarado da posição para qual foram nomeados". O senador democrata John Kerry disse que as visões de Bolton sobre controle e redução de armas eram "incompatíveis com os interesses máximos dos EUA" (BUSH..., 2001). Ver ainda Bleek (2001) e Rough... (2001).

22. A expressão "ogivas nucleares estratégicas operacionalmente desdobradas" é utilizada em referência aos veículos de reentrada nucleares em ICBMs e SLBMs nos seus lançadores e aos armamentos nucleares carregados por bombardeiros pesados ou armazenados nas suas bases.

23. Ilustrando o apoio dos senadores republicanos, Jesse Helms - crítico do CTBT e do ABMT - afirmou que a vulnerabilidade deliberada a um ataque de mísseis era uma "falta de juízo" e que os membros do Executivo russo deveriam conscientizar-se de que a Guerra Fria tinha acabado; logo, para Helms, "era hora de jogar fora o ABMT" (BUSH..., 2001). Além disso, o senador via a necessidade de atualização do pensamento estratégico norte-americano, julgando apropriadas as propostas do presidente de considerar reduções significativas. Porém, Helms indicou que, a fim de lidar com novas ameaças e desafios, o país também precisava de novos modelos de armas capazes de atingir alvos subterrâneos. Jon Kyl apontou que já era hora de os EUA reconhecerem a vulnerabilidade conservada pelo ABMT; logo, assim como a Cortina de Ferro ruíra, o tratado deveria ter o mesmo destino. Além de parabenizar Bush pela liderança na condução das questões relacionadas à defesa antimísseis, James Inhofe enfatizou o contraste da visão de Bush com a perspectiva morosa de Clinton sobre questões de segurança estratégica (BUSH..., 2001).

24. O senador democrata Joseph Biden, por exemplo, duvidava que líderes de Estados-párias atacassem os EUA “da noite para o dia”. Segundo Carl Levin, a defesa antimísseis seria desdobrada independentemente do resultado das negociações com os demais países envolvidos e faltava conhecimento sobre as consequiências do desdobramento de tais sistemas. Jack Reed defendeu que a posição de Bush carecia de elementos que efetivamente apontassem para a preservação da estabilidade estratégica. Já Thomas Daschle não compreendia como se poderia apoiar um programa que não funcionava, em referência à defesa antimísseis. Ele ressaltou que violar ou modificar o ABMT sem ter a certeza de que 
a defesa antimísseis funcionaria perfeitamente era "tolice absoluta". Richard Durbin apontou que seria um "desatino" abandonar o ABMT antes de se chegar perto de uma defesa antimísseis que funcionasse. Para Durbin, a posição de Bush era "um convite para uma nova corrida armamentista global" (BUSH..., 2001). O senador John Kerry concluiu que, caso não se pudesse abater $100 \%$ de mísseis lançados, ainda não se tinha deixado de lado a destruição mutuamente assegurada. Porém, se a defesa antimísseis ideal fosse possível, dar-se-ia início a uma corrida armamentista para desenvolver capacidades que não pudessem ser eliminadas por tal sistema (BUSH..., 2001).

25. Bush e Putin diziam que seus países haviam embarcado em um "novo relacionamento para o século XXI", baseado em um compromisso com "a democracia, o livre mercado e o domínio da lei”. Tal relação proveria bases para o combate ao terrorismo, à proliferação de WMD, ao nacionalismo militante, à intolerância étnico-religiosa e à instabilidade regional, vistos como as principais ameaças do século. Os líderes concordaram que os níveis correntes das forças nucleares não refletiam as realidades estratégicas do mundo contemporâneo e firmaram os compromissos de implementar reduções ofensivas estratégicas substanciais e de dar continuidade às consultas sobre defesas estratégicas. Eles reafirmaram o compromisso com a Convenção sobre Armas Químicas e a Convenção sobre Armas Biológicas e apoiaram os esforços para o fortalecimento do TNP (ESTADOS UNIDOS DA AMÉRICA. Casa Branca, 2001).

26. A sigla remete a dois ou mais veículos de reentrada carregados por um único míssil, dirigíveis para alvos distintos e separados.

27. As principais preocupações de Putin eram a recuperação e a modernização econômica da Rússia. Para conduzir tal processo ainda embrionário, o país precisaria do acesso ao capital, à tecnologia e aos mercados ocidentais. O crescimento econômico também poderia ser essencial para o futuro político de Putin, que sabia que a Rússia só poderia se reerguer por meio do fortalecimento de sua posição nos mercados globais, como ocorrera com a China após a modernização econômica implementada por Deng Xiaoping vinte anos antes. Além disso, havia uma tendência crescente na Rússia a ver o Ocidente - notavelmente os EUA - como parceiro de segurança na Eurásia. Seria um equívoco dizer que membros do governo Putin se mostravam satisfeitos com a presença militar norte-americana na Ásia Central e na Geórgia, já que temiam a potencial perda de uma esfera tradicional de influência. Porém, como Putin declarara, havia ameaças reais na periferia meridional da Rússia, como o terrorismo, o extremismo religioso e o tráfico de drogas. Os membros do Executivo russo desejavam combater tais ameaças, mas percebiam que, sozinhos, não teriam recursos para isso. Os russos certamente não se sentiam confortáveis com a profunda assimetria de poder, mas tinham a noção de que, se quisessem ter acesso aos benefícios 


\section{Diego Santos Vieira de Jesus}

da cooperação político-econômica com o Ocidente, deveriam pagar alguns preços. Putin acreditou que, ao se tornar um membro do "clube ocidental", a Rússia teria mais influência na definição das "regras do jogo" (GADDY et al., 2002; GOLDGEIER et al., 2002; KUCHINS, 2002; LODGAARD, 2003).

28. Na declaração, ambos os lados reafirmaram o interesse no combate à proliferação de WMD, ao terrorismo internacional e ao narcotráfico, além do interesse nas ações humanitárias e na resolução de conflitos regionais, como em Abkhazia e em Nagorno-Karabakh. Além disso, anunciaram que, em poucos dias, seria estabelecido, em Roma, o Conselho Rússia-OTAN, cujos membros visariam identificar perspectivas comuns para a segurança. Ademais, reconhecendo a importância da economia de mercado, da livre iniciativa e dos valores democráticos para o bem-estar dos cidadãos, ambos os países também se comprometiam a ampliar a cooperação econômica. Os EUA prometeram eliminar barreiras comerciais nas relações com a Rússia e a dar prioridade ao acesso desse país à Organização Mundial do Comércio. Na área social, eram previstos esforços para a resolução de problemas nos setores de educação e de saúde-como programas de combate à AIDS e a outras doenças - e nos relacionados ao meio ambiente (BUSH; PUTIN, 2002; CENTER FOR ARMS CONTROL AND NON-PROLIFERATION, 2002; 2003).

29. Os membros do Executivo de cada lado "resolveram" tal questão destinando-a à Declaração Conjunta sobre a Nova Relação Estratégica. A cooperação incluiria troca de informação e visitas recíprocas para observação de testes. As partes concordaram em realizar exercícios conjuntos e estabelecer programas de pesquisa e desenvolvimento (WOOLF, 2002).

30. No caso específico de reduções ofensivas estratégicas, a legislação doméstica norte-americana proibia o uso de acordos que não fossem legalmente vinculantes, a menos que houvesse a autorização do Congresso. Isso não necessariamente proíbe que os EUA utilizem perspectivas que sejam menos formais que as tradicionais ou que não sejam legalmente vinculantes. Apenas significa que o presidente deve obter o consentimento congressual tanto antes como depois de ter atingido o acordo. Em um momento em que se poderia tornar necessário acomodar os requerimentos de segurança e também manter alguma proteção contra os riscos, preservando a liberdade para responder a mudanças repentinas no ambiente de segurança e explorar novas tecnologias menos dispendiosas, havia diversas formas para se construir flexibilidade, criando perspectivas híbridas que combinavam aos acordos formais legalmente vinculantes alguns elementos mais característicos de perspectivas que não o são. Dentre elas, cabe citar a incorporação de termos e de limites flexíveis ao acordo e a limitação de sua duração (KARTCHNER; PITMAN, 2002). 
31. No Senado, Powell e Rumsfeld procuraram enfatizar o caráter inovador do tratado, que, nas palavras do secretário de Estado, representava o compromisso de ambos os países de realizar reduções ofensivas estratégicas amplas de uma forma ao mesmo tempo flexível e legalmente vinculante, que facilitaria a transição "da rivalidade estratégica para uma parceria estratégica genuína" (POWELL, 2002). Rumsfeld indicou que os representantes de cada lado conseguiram preservar benefícios do processo de controle e de redução de armas como as consultas, os níveis menores de forças, a previsibilidade e a transparência-, mas evitaram os principais obstáculos, como extensos e amargos debates sobre aquiescência e prestação de contas (RUMSFELD, 2002b). Powell e Rumsfeld disseram que o plano era armazenar até 2.400 ogivas removidas de serviço, que estariam prontas para redesdobramento em semanas, meses ou anos. Outras ogivas e componentes seriam mantidos como reservas ou em estágios menores de prontidão (BOESE, 2002b).

\section{Referências Bibliográficas}

ABBOTT, K.; KEOHANE, R.; MORAVCSIK, A.; SLAUGHTER, A.-M.; SNIDAL, D. The concept of legalization. International Organization, v. 54, n. 3, p. 401-419, 2000.

ALLISON, G. Essence of decision: explaining the Cuban missile crisis. Boston: Little, Brown, 1971.

ALMEIDA, M. H. T. Prefácio. In: PRZEWORSKI, A. Capitalismo e social-democracia. São Paulo: Companhia das Letras, 1989. p. 7-10.

APPLEGARTH, C. The 2000 NPT Review Conference and the 13 Practical Steps: a summary. Arms Control Today, v. 35, n. 1, jan.-fev. 2005. Disponível em: <http://www.armscontrol.org/act/2005_01-02/Scheinman.asp >. Acesso em: 11 jul. 2006.

ARBATOV, A. Superseding U.S.-Russian nuclear deterrence. Arms Control Today, v. 35, n. 1, jan.-fev. 2005. Disponível em: <http://www.armscontrol.org/act/2005_01-02/Arbatov.asp>. Acesso em: 11 jul. 2006. 


\section{Diego Santos Vieira de Jesus}

BARTON, J. H.; WEILER, L. D. (Ed.). International arms control: issues and agreements. Stanford: Stanford University Press, 1976.

BLEEK, P. C. Senate narrowly confirms Bolton to top arms control post. Arms Control Today, v. 31, n. 5, jun. 2001. Disponível em: <http://www.armscontrol.org/act/2001_06/boltonjun01.asp>. Acesso em: 24 jul. 2004.

Nuclear Posture Review leaks; outlines targets, contingencies. Arms Control Today, v. 32, n. 3, abr. 2002a. Disponível em: <http://www.armscontrol.org/act/2002_04/nprapril02.asp>. Acesso em: 24 jul. 2004.

. U.S., Russia sign treaty cutting deployed nuclear forces. Arms Control Today, v. 32, n. 5, jun. 2002b. Disponível em: <http://www.armscontrol.org/act/2002_06/sortjune02.asp>. Acesso em: 24 jul. 2004.

BOESE, W. Bush assembles pro-missile defense national security team. Arms Control Today, v. 31, n. 1, jan.-fev. 2001a. Disponível em: <http://www.armscontrol.org/act/2001_01-02/bushjanfeb01.asp>. Acesso em: 24 jul. 2004.

. Bush administration stresses commitment to missile defense. Arms Control Today, v. 31, n. 2, mar. 2001b. Disponível em: <http://www.armscontrol.org/act/2001_03/bushnmd.asp>. Acesso em: 24 jul. 2004.

Bush pushes new strategic framework, missile defenses. Arms Control Today, v. 31, n. 5, jun. 2001c. Disponível em: <http://www.armscontrol.org/ act/2001_06/speechjun01.asp>. Acesso em: 24 jul. 2004.

. Democrats say debate on missile defense is not over. Arms Control Today, v. 31, n. 9, nov. 2001d. Disponível em: <http://www.armscontrol.org/act/ 2001_11/misdefnov01.asp>. Acesso em: 24 jul. 2004.

. No Bush-Putin agreement on ABM Treaty, missile defenses. Arms Control Today, v. 31, n. 10, dez. 2001e. Disponível em: <http://www.armscontrol.org/act/2001_12/misdefdec01.asp>. Acesso em: 24 jul. 2004.

. Bush announces U.S. intent to withdraw from ABM Treaty. Arms Control Today, v. 32, n. 1, jan.-fev. 2002a. Disponível em: <http://www.armscontrol.org/act/2002_01-02/abmjanfeb02.asp>. Acesso em: 24 jul. 2004.

Senate reviews U.S.-Russian nuclear reductions treaty. Arms Control Today, v. 32, n. 7, set. 2002b. Disponível em: <http://www.armscontrol.org/ act/2002_09/moscowtreaty_sept02.asp>. Acesso em: 24 jul. 2004. 
Senate approves new U.S. ambassador to CD. Arms Control Today, v. 34, n. 1, jan.-fev. 2004a. Disponível em: <http://www.armscontrol.org/act/2004_01-02/CD.asp>. Acesso em: 24 jun. 2007.

Congress axes funding for new nukes. Arms Control Today, v. 34, n. 10, dez. 2004b. Disponível em: <http://www.armscontrol.org/act/2004_12/NewNukes.asp>. Acesso em: 24 jun. 2007.

The United States on key nuclear issues. Arms Control Today, v. 35, n. 1, jan.-fev. 2005a. Disponível em: <http://www.armscontrol.org/act/2005_ 01-02/Scheinman.asp>. Acesso em: 11 jul. 2006.

Bunker buster future uncertain. Arms Control Today, v. 35, n. 6, jul.-ago. 2005b. Disponível em: <http://www.armscontrol.org/act/2005_0708/Bunker_Buster.asp>. Acesso em: 11 jul. 2006.

BOLTON, J. R. John Bolton interview. Disarmament Diplomacy, n. 59, jul.-ago. 2001. Disponível em: <http://www.acronym.org.uk/dd/dd59/59docs 11.htm>. Acesso em: 25 jul. 2004.

BREMMER, I.; CHARAP, S. The siloviki in Putin's Russia: who they are and what they want. The Washington Quarterly, v. 30, n. 1, p. 83-92, inverno 2006-2007.

BUKHARIN, O.; DOYLE, J. Transparency and predictability measures for U.S. and Russian strategic arms reductions. The Nonproliferation Review, v. 9, n. 2, p. 1-19, 2002.

BUSH team confirmation hearings. Disarmament Diplomacy, n. 53, dez. 2000-jan. 2001a. Disponível em: <http://www.acronym.org.uk/dd/dd53/ 53bush.htm>. Acesso em: 25 jul. 2004.

BUSH team stresses missile defence as Russia champions ABM Treaty. Disarmament Diplomacy, n. 53, dez. 2000-jan. 2001b. Disponível em: <http:/ /www.acronym.org.uk/dd/dd53/53stres.htm>. Acesso em: 25 jul. 2004.

BUSH speech on missile defence, nuclear reductions. Disarmament Diplomacy, n. 56, abr. 2001. Disponível em: <http://www.acronym.org.uk/dd/dd56/ 56bush.htm>. Acesso em: 25 jul. 2004.

BUSH, G. W.; PUTIN, V. Remarks by President Bush and President Putin at signing of Joint Declaration and press availability, The Kremlin, May 24, 2002. Disarmament Documentation, mai. 2002. Disponível em: <http://www. acronym.org.uk/docs/0205/doc07.htm\#usfact>. Acesso em: 25 jul. 2004. 
CENTER FOR ARMS CONTROL AND NON-PROLIFERATION. Briefing book on the Bush-Putin summit and the U.S. Nuclear Posture Review. Washington, DC, 2002. Disponível em: <http://www.armscontrolcenter. org/ 2002summit>. Acesso em: 26 jul. 2004.

Briefing book on Strategic Offensive Reductions Treaty or Treaty of Moscow. Washington, DC, 2003. Disponível em: <http://www.clw.org/control/sort-briefing-book.pdf>. Acesso em: 26 jul. 2004.

CIRINCIONE, J.; GRONLUND, L.; KIMBALL, D. G.; RHINELANDER, J. ABM Treaty withdrawal: neither necessary nor prudent. Arms Control Today, v. 32, n. 1, jan.-fev. 2002. Disponível em: <http://www.armscontrol.org/ act/2002_01-02/pressconjanfeb02.asp>. Acesso em: 24 jul. 2004.

CIRINCIONE, J.; WOLFSTHAL, J. B. What if the new strategic framework goes bad? Arms Control Today, v. 31, n. 9, nov. 2001. Disponível em: $<$ http://www.armscontrol.org/act/2001_11/cirincionenov01.asp >. Acesso em: 24 jul. 2004.

CROUCH, J. D. Remarks by J. D. Pentagon Briefing, January 9. Special Pentagon Briefing on the Nuclear Posture Review, January 9. Disarmament Documentation, jan. 2002. Disponível em: <http://www.acronym.org.uk/docs/ 0201/doc01.htm>. Acesso em: 25 jul. 2004.

DAALDER, I. H.; LINDSAY, J. M. One-day wonder: the dangerous absurdity of the Bush-Putin arms treaty. The American Prospect, v. 13, n. 15, ago. 2002. Disponível em: <http://www.prospect.org/print/V13/15/daalder-i.html>. Acesso em: 26 jul. 2004.

DAVIS, R. A. Nuclear offensive arms reductions - past and present. U.S. Foreign Policy Agenda, v. 7, n. 2, jul. 2002. Disponível em: <http://usinfo.state. gov/journals/itps/0702/ijpe/davis.htm>. Acesso em: 27 jul. 2004.

DUMA postpones ratification of Moscow Treaty on eve of US-led war in Iraq. Disarmament Diplomacy, n. 70, abr.-mai. 2003. Disponível em: <http:// www.acronym.org.uk/dd/dd70/70ddnr05.htm>. Acesso em: 25 jul. 2004.

DUTTA, P. K. Strategies and games: theory and practice. Cambridge, Massachusetts: MIT Press, 1999.

ELLIS, J. D. The best defense: counterproliferation and U.S. national security. The Washington Quarterly, v. 26, n. 2, p. 115-133, primavera 2003. 
ESTADOS UNIDOS DA AMÉRICA. Constituição (1787). Artigo II. Seção 2. Cláusula 1. The President shall be Commander in Chief of the Army and Navy of the United States, and of the Militia of the several States, when called into the actual Service of the United States; he may require the Opinion, in writing, of the principal Officer in each of the executive Departments, upon any Subject relating to the Duties of their respective Offices, and he shall have Power to grant Reprieves and Pardons for Offences against the United States, except in Cases of Impeachment. The United States Constitution, Washington, DC, s.d. Disponível em: <http://www.house.gov/Constitution/Constitution.html>. Acesso em: 11 set. 2004.

ESTADOS UNIDOS DA AMÉRICA. Casa Branca. History of the National Security Council, 1947-1997. National Security Council, Washington, DC, 1997. Disponível em: <http://www.whitehouse.gov/nsc/history.html>. Acesso em: 11 set. 2004.

Joint statement on new U.S.-Russian relationship. Current News, Washington, DC, 14 nov. 2001. Disponível em: <http://www.whitehouse.gov/ news/releases/2001/11/20011113-4.html>. Acesso em: 28 jul. 2004.

ESTADOS UNIDOS DA AMÉRICA. Departamento de Defesa. Top civilian and military leaders. DoD Websites. Washington, DC, set. 2004. Disponível em: <http://www.defenselink.mil/osd/topleaders.aspx>. Acesso em: 11 set. 2004.

ESTADOS UNIDOS DA AMÉRICA. Departamento de Estado. Duties of the Secretary of State. Fact sheet, jan. 2001. Disponível em: <http://www.state. gov/secretary/96.htm>. Acesso em: 11 set. 2004.

FEDERAÇÃO RUSSA. Ministério das Relações Exteriores. Russian Foreign Ministry Statement. On the adoption by State Duma of the Federal Assembly of the Russian Federation of a Federal Law on ratification of the Treaty between the Russian Federation and the United States of America on Strategic Offensive Reductions. Disarmament Documentation, mai. 2003. Disponível em: $<$ http://www.acronym.org.uk/docs/0305/doc08.htm01>. Acesso em: 25 jul. 2004.

FEITH, D. US Congressional Testimony, February 2002. Disarmament Documentation, fev. 2002. Disponível em: <http://www.acronym.org.uk/docs/ 0202/doc06.htm>. Acesso em: 25 jul. 2004.

FUERTH, L. Return of the nuclear debate. The Washington Quarterly, v. 24, n. 4, p. 97-108, outono 2001. 
GADDY, C.; HILL, F.; LINDSAY, J. M.; STEINBERG, J. B. Preview of president Bush's trip to Russia: assessing current relations between Moscow and Washington. In: BROOKINGS INSTITUTION PANEL DISCUSSION. Brookings press briefing. Washington, DC: Brookings Institution, 2002. Disponível em: <http://www.brook.edu/comm/transcripts/20020509.htm>. Acesso em: 26 jul. 2004.

GLASER, C. L.; FETTER, S. National missile defense and the future of U.S. nuclear weapons policy. International Security, v. 26, n. 1, p. 40-92, verão 2001.

GOLDGEIER, J.; MCFAUL, M. George W. Bush and Russia: the great reversal. Current History, v. 101, n. 657, out. 2002. Disponível em: <http://www. currenthistory.com/pdf_files/101/657/101_657_313.pdf>. Acesso em: 26 jul. 2004.

; GOTTEMOELLER, R.; KUCHINS, A. Russia after the fall. In: RUSSIAN EURASIAN AFFAIRS PROGRAM EVENTS - CARNEGIE ENDOWMENT FOR INTERNATIONAL PEACE PANEL DISCUSSION, 518. Is the U.S.-Russia partnership working? Washington, DC: Carnegie Endowment for International Peace, 2002. Disponível em: <http://www.ceip. org/files/events/2002-10-10-us-russia-tscript.asp>. Acesso em: 26 jul. 2004.

GOTTEMOELLER, R. Offense, defense, and unilateralism in strategic arms control. Arms Control Today, v. 31, n. 7, set. 2001. Disponível em: <http:// www.armscontrol.org/act/2001_09/gottemoellersept01.asp>. Acesso em: 24 jul. 2004.

. Arms control in a new era. The Washington Quarterly, v. 25, n. 2, primavera 2002. Disponível em: <http://www.twq.com/02spring/gottemoeller. pdf>. Acesso em: 27 jul. 2004.

Nuclear necessity in Putin's Russia. Arms Control Today, v. 34, n. 3, abr. 2004. Acesso em: <http://www.armscontrol.org/act/2004_04/Gottemoeller.asp>. Acesso em: 12 jul. 2006.

HALPERIN, M. H.; GOTTEMOELLER, R; KIMBALL, D. G.; NOLAN, J. E. Parsing the Nuclear Posture Review. Arms Control Today, v. 32, n. 2, mar. 2002. Disponível em: <http://www.armscontrol.org/act/2002_03/panelmarch02.asp>. Acesso em: 24 jul. 2004.

HOLUM, J. Assessing the new U.S.-Russian pact. Arms Control Today, v. 32, n. 5, jun. 2002. Disponível em: <http://www.armscontrol.org/act/2002_06/holumjune02.asp>. Acesso em: 24 jul. 2004. 
HUNTLEY, W. L. Threats all the way down: US strategic initiatives in a unipolar world. Review of International Studies, n. 32, p. 49-67, 2006.

INTERNATIONAL developments, May 1 - July 10, 2003. Moscow Treaty enters into force. Disarmament Diplomacy, News Review Special Edition, $\mathrm{n}$. 72, ago.-set. 2003. Disponível em: <http://www.acronym.org.uk/dd/ dd72/72 nr06.htm>. Acesso em: 25 jul. 2004.

IVANOV, S. B. Russian leaders regard the maintenance of fighting ability and readiness of strategic nuclear forces as their top priority task, Russian Defence Minister Ivanov, July 13, 2004. Disarmament Documentation, jul. 2004. Disponível em: <http://www.acronym.org.uk/docs/0407/doc04.htm>. Acesso em: 12 jul. 2006.

JESUS, D. S. V . Além da Guerra Fria: a maximização da flexibilidade estratégica norte-americana e o Tratado de Moscou (2002). Dissertação (Mestrado em Relações Internacionais) - Instituto de Relações Internacionais da Pontifícia Universidade Católica do Rio de Janeiro, Rio de Janeiro, 2005.

JISHE, F. Nagging uncertainty and growing concern: the Bush administration's arms control policy. Disarmament Diplomacy, n. 55, mar. 2001. Disponível em: <http://www.acronym.org.uk/dd/dd55/55doubt.htm>. Acesso em: 25 jul. 2004.

JOHNSON, R. Politics and protection: why the 2005 NPT Review Conference failed. Disarmament Diplomacy, n. 80, outono 2005. Disponível em: <http://www.acronym.org.uk/dd/dd80/80npt.htm>. Acesso em: 11 jul. 2006.

KARTCHNER, K. M. The future of the offense-defense relationship. In: LARSEN, J. (Ed.). Arms control: cooperative security in a changing environment. Londres; Boulder: Lynne Rienner Publishers, 2002. p. 271-289.

; PITMAN, G. R. Alternative approaches to arms control in a changing world. Disarmament Diplomacy, n. 62, jan.-fev. 2002. Disponível em: <http://www.acronym.org.uk/dd/dd62/62op1.htm>. Acesso em: 25 jul. 2004.

KATZENSTEIN, P.; KEOHANE, R.; KRASNER, S. International Organization and the study of world politics. International Organization, v. 52, n. 4, p. 645-686, 1998.

KERREY, R.; HARTUNG, W. D. Toward a new nuclear posture: challenges for the Bush administration. Arms Control Today, v. 31, n. 3, abr. 2001. Disponível em: <http://www.armscontrol.org/act/2001_04/kerrey.asp>. Acesso em: 24 jul. 2004. 


\section{Diego Santos Vieira de Jesus}

KIMBALL, D. G. Fuzzy nuclear math. Arms Control Today, v. 31, n. 10, dez. 2001. Disponível em: <http://www.armscontrol.org/act/2001_12/focdec01. asp>. Acesso em: 24 jul. 2004.

A beginning, not an end. Arms Control Today, v. 32, n. 5, jun. 2002. Disponível em: <http://www.armscontrol.org/act/2002_06/focjune02.asp>. Acesso em: 24 jul. 2004.

Nuclear checks and balances. Arms Control Today, v. 34, n. 10, dez. 2004. Disponível em: <http://www.armscontrol.org/act/2004_12/Focus.asp>. Acesso em: 24 jun. 2007.

Nonproliferation through disarmament. Arms Control Today, v. 35, n. 1, jan.-fev. 2005a. Disponível em: <http://www.armscontrol.org/act/ 2005_01-02/focus.asp>. Acesso em: 11 jul. 2006.

Keeping test ban hopes alive: the 2005 CTBT Entry-into-force Conference. Disarmament Diplomacy, n. 81, inverno 2005b. Disponível em: $<$ http://www.acronym.org.uk/dd/dd81/81dk.htm>. Acesso em: 16 jul. 2006.

; KUCIA, C. New nuclear policies, new weapons, new dangers. Arms Control Today, v. 33, n. 3, abr. 2003. Disponível em: <http://www.armscontrol.org/factsheets/newnuclearweaponsissuebrief.asp $>$. Acesso em: 24 jul. 2004.

KRISTENSEN, H. M. The unruly hedge: Cold War thinking at the Crawford Summit. Arms Control Today, v. 31, n. 10, dez. 2001. Disponível em: $<$ http://www.armscontrol.org/act/2001_12/kristensennov01.asp >. Acesso em: 24 jul. 2004.

. The role of U.S. nuclear weapons: new doctrine falls short of Bush pledge. Arms Control Today, v. 35, n. 7, set. 2005. Disponível em: <http://www.armscontrol.org/act/2005_09/Kristensen.asp>. Acesso em: 11 jul. 2006.

KUCHINS, A. C. Explaining Mr. Putin: Russia's new nuclear diplomacy. Arms Control Today, v. 32, n. 8, out. 2002. Disponível em: $<$ http://www.armscontrol.org/act/2002_10/kuchinsoct02.asp>. Acesso em: 24 jul. 2004.

KUCIA, C. U.S., Russian legislatures take up SORT ratification. Arms Control Today, v. 33, n. 2, mar. 2003a. Disponível em: <http://www.armscontrol. org/act/2003_03/sort_mar03.asp>. Acesso em: 24 jul. 2004. 
Senate endorses nuclear reductions treaty; Duma delays. Arms Control Today, v. 33, n. 3, abr. 2003b. Disponível em: <http://www.armscontrol.org/ act/2003_04/sortratification_apr03.asp>. Acesso em: 24 jul. 2004.

Russia mulls altered nuclear doctrine. Arms Control Today, v. 33, n. 9, nov. 2003c. Disponível em: <http://www.armscontrol.org/act/2003_11/Russiannucleardoctrine.asp $>$. Acesso em: 11 jul. 2006.

KUPCHAN, C. The end of the American era: U.S. foreign policy and the geopolitics of the twenty-first century. New York: A. Knopf, 2002.

LARSEN, J. (Ed.). Arms control: cooperative security in a changing environment. Londres; Boulder: Lynne Rienner Publishers, 2002.

National security and neo-arms control in the Bush administration. Disarmament Diplomacy, n. 80, outono 2005. Disponível em: <http://www. acronym.org.uk/dd/dd80/80jal.htm>. Acesso em: 15 jul. 2005.

LIEVEN, A. The secret policemen's ball: the United States, Russia and the international order after 11 September. International Affairs, v. 78, n. 2, p. 245-259, 2002.

LODGAARD, S. Good news for non-proliferation? The changing relationship between Russia, NATO and the NPT. Disarmament Diplomacy, n. 69, fev.-mar. 2003. Disponível em: <http://www.acronym.org.uk/dd/ dd69/69op02.htm>. Acesso em: 25 jul. 2004.

MENDELSOHN, J. The US Nuclear Posture Review: plus ça change, plus c'est la même chose. Disarmament Diplomacy, n. 64, mai.-jun. 2002. Disponível em: <http://www.acronym.org.uk/dd/dd64/64op1.htm>. Acesso em: 25 jul. 2004.

MILLER, F.; GOTTEMOELLER, R.; PAINE, C.; SMITH, D. J.; BURNS, W. F. US nuclear policy. In: CARNEGIE INTERNATIONAL NONPROLIFERATION CONFERENCE. 2002, Washington, D.C. Anais eletrônicos... Washington, D.C.: Carnegie Endowment for International Peace, 2002. Disponível em: <http://www.ceip.org/files/projects/npp/resources/conference2002/ usnuclearpolicy.htm>. Acesso em: 27 jul. 2004.

MILNER, H. Interests, institutions and information: domestic politics and international relations. Princeton: Princeton University Press, 1997.

MORAVCSIK, A. Introduction: integrating international and domestic theories of international bargaining. In: EVANS, P.; JACOBSON, H. K.; PUTNAM, 
R. (Ed.). Double-edged diplomacy: international bargaining and domestic politics. Berkeley, LA: University of California Press, 1993. p. 3-42.

MOSCOW Treaty on hold over Iraq as US pushes new thinking on nuclear weapons. Disarmament Diplomacy, n. 71, jun.-jul. 2003. Disponível em: <http://www.acronym.org.uk/dd/dd71/71ddnr05.htm>. Acesso em: 25 jul. 2004.

NEWHOUSE, J. The missile defense debate. Foreign Affairs, v. 80, n. 4, jul.-ago. 2001.

NORRIS, R. S.; KRISTENSEN, H. M. Russian nuclear forces, 2004. Bulletin of the Atomic Scientists, v. 60, n. 4, jul.-ago. 2004. Disponível em: <http:// www.thebulletin.org/article_nn.php?art_ofn=ja04norris $>$. Acesso em: 11 jul. 2006.

. Russian nuclear forces, 2005. Bulletin of the Atomic Scientists, v. 61, n. 2, mar.-abr. 2005. Disponível em: <http://www.thebulletin.org/article_ nn.php?art_ofn=ma05norris $>$. Acesso em: 11 jul. 2006.

O'HANLON, M. The new U.S.-Russian strategic framework: a preliminary assessment. U.S. Foreign Policy Agenda, v. 7, n. 2, jul. 2002. Disponível em: <http://usinfo.state.gov/journals/itps/0702/ijpe/o'hanlon.htm>. Acesso em: 27 jul. 2004.

PAYNE, K. B. The Nuclear Posture Review: setting the record straight. The Washington Quarterly, v. 28, n. 3, p. 135-151, verão 2005.

PIKAYEV, A. The future of U.S.-Russian nuclear relations: a Rip van Winkle approach? Program on New Approaches to Russian Security (PONARS) Policy Memos, n. 276, 2002. Disponível em: <http://www.csis.org/ruseura/ponars/policymemos/pm_0276.pdf>. Acesso em: 26 jul. 2004.

PODVIG, P. Who is in charge? Russia handles arms control negotiations. Program on New Approaches to Russian Security (PONARS) Policy Memos, n. 277, 2002. Disponível em: <http://www.csis.org/ruseura/ponars/policymemos/pm_0277.pdf>. Acesso em: 26 jul. 2004.

POWELL, C. A new way of doing business: Powell testimony on Moscow Treaty, July 9. Disarmament Documentation, jul. 2002. Disponível em: $<$ http://www.acronym.org.uk/docs/0207/doc01.htm>. Acesso em: 25 jul. 2004. 
; IVANOV, I. Remarks by Russian Foreign Minister and US Secretary of State. "Press availability: Secretary of State Colin L. Powell and Russian Foreign Minister Igor Ivanov, Russian Ministry of Foreign Affairs, Moscow, Russia, May 14, 2003". Disarmament Documentation, mai. 2003. Disponível em: <http://www.acronym.org.uk/docs/0305/doc08.htm>. Acesso em: 25 jul. 2004.

PREEZ, J. D. The impact of the Nuclear Posture Review on the International Nuclear Nonproliferation Regime. The Nonproliferation Review, v. 9, n. 3, p. 67-81, outono-inverno 2002.

The Fissban: time for renewed commitment or a new approach? Disarmament Diplomacy, n. 79, abr.-mai. 2005. Disponível em: <http://www. acronym.org.uk/dd/dd79/79jp.htm>. Acesso em: 17 jul. 2005.

PUTNAM, R. Diplomacy and domestic politics: the logic of two-level games. International Organization, v. 42, n. 3, p. 427-460, 1988.

QUINTELLA, T. M. M. A Rússia e o Ocidente na pós-pós-Guerra Fria. Panorama da Conjuntura Internacional, n. 14, jul.-set. 2002. Disponível em: $<$ http://www.usp.br/ccint/gacint/panorama.html>. Acesso em: 15 out. 2003.

RAUF, T. Towards NPT 2005: an action plan for the "13-steps" towards nuclear disarmament agreed at NPT 2000. Monterey: Center for Nonproliferation Studies, Monterey Institute of International Studies, 2001.

ROUGH ride for Bush arms control nominee. Disarmament Diplomacy, $\mathrm{n}$. 56, abr. 2001. Disponível em: <http://www.acronym.org.uk/dd/dd56/ 56bolt.htm>. Acesso em: 25 jul. 2004.

RUMER, E. B.; WALLANDER, C. A. Russia: power in weakness? The Washington Quarterly, v. 27, n. 1, p. 57-73, inverno 2003-2004.

RUMSFELD, D. US Nuclear Posture Review (NPR), January 8. Letter to Congress from US Defense Secretary, January 8. Nuclear Posture Review report: foreword, cover letter submitting classified report to Congress on the Nuclear Posture Review. Disarmament Documentation, jan. 2002a. Disponível em: $<$ http://www.acronym.org.uk/docs/0201/doc01.htm>. Acesso em: 25 jul. 2004.

Moving towards a post-arms control relationship: Rumsfeld testimony on Moscow Treaty, July 17. Disarmament Documentation, jul. 2002b. Disponí- 


\section{Diego Santos Vieira de Jesus}

vel em: <http://www.acronym.org.uk/docs/0207/doc04.htm>. Acesso em: 25 jul. 2004.

SCHEINMAN, L. Disarmament: have the five nuclear powers done enough? Arms Control Today, v. 35, n. 1, jan.-fev. 2005. Disponível em: <http://www. armscontrol.org/act/2005_01-02/Scheinman.asp>. Acesso em: 11 jul. 2006.

SIMS, J. E. Domestic factors in arms control: the U.S. case. In: LARSEN, J. (Ed.). Arms control: cooperative security in a changing environment. Londres, Boulder: Lynne Rienner Publishers, 2002. p. 55-78.

SMITH, J. A tale of two countries: Russia, North Korea, and the present and future of arms control, nonproliferation, and counterproliferation in United States policy. In: $45^{\mathrm{TH}}$ INTERNATIONAL STUDIES ASSOCIATION ANNUAL CONVENTION, 2004, Montreal. Paper archive. Tucson, Arizona: International Studies Association, 2004. Disponível em: <http://archive.allacademic.com/publication/getfile.php?file=docs/isa_proceeding/2004-03-11/13130/isa_proceeding_13130.PDF\&PHPSESSID $=788627 \mathrm{f} 3 \mathrm{~d} 9755 \mathrm{~d} 945 \mathrm{e} 3008 \mathrm{e} 7 \mathrm{fcf} 2 \mathrm{a} 6 \mathrm{a} 0>$. Acesso em: 28 mar. 2004.

SOKOV, N. The ABM Treaty: the end of one saga and the start of another. Program on New Approaches to Russian Security (PONARS) Policy Memos, n. 218, 2001. Disponível em: <http://www.csis.org/ruseura/ponars/policymemos/pm_0218.pdf>. Acesso em: 26 jul. 2004.

. The agenda for arms control negotiations after the Moscow Treaty. Program on New Approaches to Russian Security (PONARS) Policy Memos, n. 278, 2002. Disponível em: <http://www.csis.org/ruseura/ponars/policymemos/pm_0278.pdf>. Acesso em: 26 jul. 2004.

. The Russian nuclear arms control agenda after SORT. Arms Control Today, v. 33, n. 3, abr. 2003. Disponível em: <http://www.armscontrol.org/act/ 2003_04/sokov_apr03.asp>. Acesso em: 24 jul. 2004.

US withdrawal from ABM Treaty, December 13: announcement \& reaction. Disarmament Documentation, dez. 2001. Disponível em: <http://www. acronym.org.uk/docs/0112/doc01.htm>. Acesso em: 25 jul. 2004.

US-RUSSIA arms control breakthrough announced, May 13. Disarmament Documentation, mai. 2002. Disponível em: <http://www.acronym.org.uk/ docs/0205/doc03.htm>. Acesso em: 25 jul. 2004.

WALLER, J. M. Defense first: the national-security team is devoted to dismantling the failed defense policies that came back to haunt America on Sept. 11. 
Insight on the News, dez. 2001. Disponível em: <http://www.findarticles.com/p/articles/mi_m1571/is_48_17/ai_81391991/pg_2>. Acesso em: 13 set. 2004.

WENDT, A. Social theory of international politics. Cambridge: Cambridge University Press, 1999.

WOLFSTHAL, J. B.; CHUEN, C.-A.; DAUGHTRY, E. E. (Ed.). Nuclear status report: nuclear weapons, fissile material, and export controls in the former Soviet Union. Washington, DC: Carnegie Endowment for International Peace, 2001. Disponível em: <http://www.ceip.org/files/pdf/Status.pdf>. Acesso em: 27 jul. 2004.

WOOLF, A. F. Nuclear arms control: the Strategic Offensive Reductions Treaty. Washington, DC: Congressional Research Service, The Library of Congress, 2002. Disponível em: <http://www.usembassy.at/en/download/pdf/nucl _arms.pdf>. Acesso em: 28 jul. 2004.

YOST, D. S. New approaches to deterrence in Britain, France, and the United States. International Affairs, v. 81, n. 1, p. 83-114, 2005.

\section{Resumo}

\section{Treze Passos para o Juízo Final: A Nova Era do Desarmamento Nuclear dos Estados Unidos e da Rússia}

Este artigo procura explicar por que os líderes dos EUA e da Rússia não implementaram total e efetivamente o plano de ação de treze pontos práticos para o desarmamento nuclear, estabelecido na Conferência de Revisão do Tratado de Não-Proliferação Nuclear em 2000. As decisões relacionadas aos treze pontos, tomadas pelos membros dos Executivos das duas maiores potências nucleares, são vistas como resultado da conciliação de imperativos internos e externos por esses indivíduos, que enfrentam oportunidades e dilemas estratégicos distintos simultaneamente nos âmbitos doméstico e internacional. São consideradas as escolhas políticas de membros dos Executivos nacionais e estrangeiros, Legislativos e principais grupos de interesse desses países, bem como a distribuição de poder sobre a formulação da decisão nacional, estabelecida pelas instituições políticas domésticas. 
As hipóteses apontam que os membros dos Executivos desses países - apoiados por grande parte dos membros dos Legislativos e dos principais grupos de interesse envolvidos, como as Forças Armadas - procuraram garantir autonomia para definir a estrutura e a composição de forças estratégicas e táticas, modernizar arsenais atômicos e operar uma força capaz de lidar com contingências que envolvam não apenas potências nucleares tradicionais, mas principalmente novos Estados detentores de armas de destruição em massa e organizações terroristas.

Palavras-chave: Estados Unidos - Rússia - Desarmamento Nuclear Armas Nucleares

\section{Abstract}

\section{Thirteen Steps to Judgement Day: The New Era of Russian and North American Nuclear Disarmament}

This article aims to explain why U.S. and Russian leaders have not implemented totally and effectively the thirteen practical-step plan of action on nuclear disarmament agreed at the 2000 Nuclear Non-Proliferation Treaty Review Conference. The decisions with regard to the thirteen steps, taken by members of U.S. and Russian Executives, are seen as the result of the conciliation of internal and external imperatives by those individuals, who face distinctive strategic opportunities and dilemmas simultaneously at national and international levels. We will consider the policy choices of home and foreign Executives' members, legislators and members of the main interest groups within each country, as well as the distribution of decision-making powers by domestic political institutions. The hypotheses indicate that members of U.S. and Russian Executives - supported by a huge number of legislators and interest groups, such as Armed Forces - aim to preserve the ability to determine for themselves the structure and the composition of their strategic and tactical forces, modernize their nuclear arsenals and deploy a force to meet contingencies involving not only traditional nuclear powers, but specially rogue states and terrorist organizations.

Keywords: United States - Russia - Nuclear Disarmament - Nuclear Weapons 